\title{
Feature Interpretability in L2 Acquisition and SLI: Greek Clitics and Determiners
}

\author{
Ianthi Maria Tsimpli and Maria Mastropavlou \\ Aristotle University of Thessaloniki
}

\section{INTRODUCTION}

In recent research in language development, several attempts have been made to compare performance data from different populations (L1 or L2 learners, SLI, agrammatics) in order to provide an analysis that would account for the patterns observed, in a way that would minimize differences and maximize similarities (see, e.g., the phenomenon of Optional Infinitives in SLI grammars and L1 acquisition in Genesee, Paradis, \& Crago, 2004, Rice \& Wexler 1996). ${ }^{1}$

The aim of this chapter is to evaluate a theory of learnability based on differences in the interpretability status of formal features. This theory has been proposed for SLI children by Tsimpli and Stavrakaki (1999) and Tsimpli (2001), for L1 and L2 acquisition by Tsimpli (2003), and for L1 attrition by Sorace (2000) and Tsimpli, Sorace, Heycock and Filiaci (in press). The theory is based on the following premises: (a) a Minimalist distinction between interpretable and uninterpretable features as these are read off by each of the two interfaces, LF (Logical Form) and PF (Phonetic Form); (b) developmental differences based on the accessibility of uninterpretable features in a comparison between L1 and L2 learners as well as between normal and SLI children, and (c) compensatory strategies implemented in the case of uninterpretable features that fail to be analyzed by the developing grammar. In the following section, each of these assumptions will be articulated in more detail. The present study investigates the status of pronominal clitics and determiners in Greek SLI and in

\footnotetext{
${ }^{1}$ The reader can also consult the 2001 issue of Brain and Language for a selection of papers. We should also point out that among certain populations, notably L2 learners as well as aphasics and SLI children, individual differences are found and prevent us from grouping learners under one descriptive characterization of their linguistic performance that would adequately account for their nontarget behavior. In such cases, we look for similarities in the tendencies found in individual grammars rather than in group results.
} 


\section{Tsimpli and Mastropavlou}

the Greek L2 of adult and child learners. The comparison between SLI and L2 acquisition is based on the assumption that grammatical SLI can be viewed as a deficit in the accessibility of uninterpretable formal features and that (adult) L2 grammars also share this property, albeit for different reasons, related to critical period constraints. The motivation for the choice of clitics and determiners stems from the analysis of these items as being clusters of agreement and case features, which are uninterpretable at LF (Tsimpli \& Stavrakaki, 1999). Further differences within the paradigm of clitics and of determiners in terms of interpretability are shown to distinguish between (a) first-/second- and thirdperson accusative object clitics, (b) definite and indefinite articles, and (c) thirdperson genitive clitics in the nominal domain and third-person accusative object clitics in the verbal domain (see Tables 1-3).

In particular, whereas the definite article and the third-person clitic share the property of encoding values of uninterpretable features only, the indefinite article and first-/second-person clitics carry an interpretable feature of [definiteness] and [person] respectively. It is argued that the specification of LFinterpretable features on first-/second-person clitics and the indefinite article, and absence thereof on the definite article or the third-person clitic, gives rise to a different learnability pattern in L2 and SLI grammars. On the other hand, third-person genitive clitics in structure DPs differ from third-person accusative clitics on verbs in that the former have a richer functional content, which mirrors their thematic status as well as their referentiality (Tsimpli \& Stavrakaki, 1999). As such, genitive third-person clitics are assumed to have a higher layer of functional structure, which allows them to bear a [person] feature and, as a consequence, referentiality, contrary to third-person accusative clitics (cf. Cardinaletti \& Starke, 1999). On this basis, genitive clitics are expected to be spared in L2 acquisition and SLI, in contrast with accusative third-person clitics.

Finally, it is argued that the inaccessibility of uninterpretable features leads to a misanalysis of the third-person clitic and the definite article in advanced L2 grammars. Although misanalysis in SLI grammars has been suggested for whomission in interrogatives, the question whether child L2 and SLI data also show evidence for misanalysis of the definite article and the clitic instead of real optionality in use, remains open. In advanced adult L2 learners, nontarget performance in the use of the definite article and the third-person clitic is accounted for in terms of the assignment of the interpretable feature of [referentiality/definiteness] on these problematic elements by the L2 grammar. This assignment is possible due to the accessibility of interpretable features in any process of language development and necessary due to the inaccessibility of uninterpretable features that these two elements encode in the target language. Advanced L2 grammars are close to a steady state; in this respect, optionality could not be tolerated by the UG-constrained grammatical system. Therefore, this compensatory strategy, which involves the exploitation of interpretable features in L2 grammars, is a UG-based possibility adopted by L2 grammars when faced with problematic (due to uninterpretability) L2 input. Compensatory 
strategies of this type, that is, which involve the assignment of interpretable features on misanalyzed input have been argued to be found in SLI data (Paradis \& Gopnik, 1994, 1997; Tsimpli \& Stavrakaki, 1999) and in L2 data in Tsimpli (2003).

The chapter is organized as follows: Section 2 presents the basic assumptions on which the hypothesis of the differences in the learnability status of interpretable and uninterpretable features is built. There are three parts in this section. The first deals with the notion of interpretability in minimalism, while introducing the target Greek data; the second presents the assumptions concerning analyses of L2 and SLI data based on similarities in the inaccessibility of uninterpretable features; and the third one presents examples of compensatory strategies used by L2 learners and SLI children in cases of unanalyzed or misanalyzed input. Section 3 presents information about the subjects who participated in this study, namely, child and adult L2 learners of Greek and Greek SLI children. Section 4 includes the presentation of the results beginning with adult and child L2 learners and followed by SLI children. In section 5, the significant patterns showing differences and/or similarities between populations are discussed.

\section{THEORETICAL BACKGROUND}

\subsection{Interpretability of Grammatical Features}

In the Minimalist Program (Chomsky, 1995, 2001), features play an important role not only in the syntactic derivation but also at each of the two interface levels, PF (Phonetic Form) and LF (Logical Form). The Principle of Full Interpretation (FI), a condition that determines whether the representation converges or not, applies at each interface. FI at LF is met only when all features that are part of the representation are interpretable. In particular, features that are interpretable at LF are features with semantic import that contribute to the interpretation of the sentence. For example, features such as [definiteness], phifeatures on nouns (person, number, and gender), and the [Q] feature in interrogatives are interpretable at LF, whereas phi-features on verbs and adjectives as well as Case are uninterpretable at LF. Uninterpretable features are relevant to the syntactic derivation only. Thus, the phi-features on the verb are erased having been checked and matched with the phi-features of the subject. FI also applies at PF: PF-interpretable features are features that conform with the phonetic realization they are associated with in a particular language. Erased uninterpretable features may be converted into a phonological form at PF, according to language-specific properties (Chomsky, 1995).

The present study is concerned with the investigation of clitics and determiners in Greek. The morphological paradigm showing number, gender, and case features on articles is presented in Table 1. 
146 Tsimpli and Mastropavlou

Table 1. The definite and the indefinite articles in Greek

\begin{tabular}{lllllll}
\hline & & \multicolumn{5}{c}{ DEFINITE } \\
\hline & MASC. & & FEM. & & NEUT. & \\
CASE & SING. & PL. & SING. & PL. & SING. & PL. \\
Nominative & o & i & i & i & to & ta \\
Genitive & tu & ton & tis & ton & tu & ton \\
Accusative & ton & tus & tin & tis & to & ta \\
\hline & & & & INDEFINITE & & \\
\hline & MASC. & & FEM. & & NEUT. & \\
CASE & SING. & PL & SING. & PL. & SING. & PL. \\
Nominative & enas & - & mia & - & ena & - \\
Genitive & enos & - & mias & - & enos & - \\
Accusative & enan & - & mia & - & ena & - \\
\hline
\end{tabular}

In Table 2, the paradigm of accusative (VP-object) and genitive (possessive) clitics is presented. ${ }^{2}$

Table 2. Clitics in Greek

\begin{tabular}{|c|c|c|c|c|c|c|}
\hline \multirow[b]{2}{*}{$3^{\text {rd }}$ person } & \multicolumn{3}{|c|}{$\begin{array}{c}\text { ACCUSATIVE } \\
\text { (VP-complement) }\end{array}$} & \multicolumn{3}{|c|}{$\begin{array}{l}\text { GENITIVE } \\
\text { (Poss. in DPs) }\end{array}$} \\
\hline & MASC. & FEM. & NEUT. & MASC. & FEM. & NEUT \\
\hline SINGULAR & ton & tin & to & tu & tis & tu \\
\hline PLURAL & tus & tis & ta & tus & tus & tus \\
\hline \multicolumn{7}{|l|}{$2^{\text {nd }}$ person } \\
\hline SINGULAR & \multicolumn{3}{|c|}{ se } & \multicolumn{3}{|c|}{$\mathrm{su}$} \\
\hline PLURAL & \multicolumn{3}{|c|}{ sas } & \multicolumn{3}{|c|}{ sas } \\
\hline \multicolumn{7}{|l|}{$1^{\text {st }}$ person } \\
\hline SINGULAR & \multicolumn{3}{|c|}{ me } & \multicolumn{3}{|c|}{$\mathrm{mu}$} \\
\hline PLURAL & \multicolumn{3}{|c|}{ mas } & \multicolumn{3}{|c|}{ mas } \\
\hline
\end{tabular}

In Minimalist terms, the analysis proposed in Tsimpli and Stavrakaki (1999) is adopted. Specifically, it is assumed that Greek clitics are categorially determiners (members of the D system) which, however, are "severely deficient" in Cardinaletti and Starke's (1999) terms. In particular, their "deficiency" is morphosyntactic as well as semantic and is contrasted with strong pronouns, which involve a richer structure with a functional layer associated with referentiality. Furthermore, in Tsimpli and Stavrakaki (1999) a distinction is drawn between first- and second-person clitics on one hand, and third-person object clitics on the other: third-person clitics are clusters of uninterpretable case and agreement features only, whereas first- and second-

\footnotetext{
${ }^{2}$ Greek has no subject clitics and no reflexive clitics.
} 
person clitics also bear an interpretable [person] feature (Manzini \& Savoia, 1998). ${ }^{3}$

Furthermore, Tsimpli and Stavrakaki (1999) suggest that accusative clitics differ from genitive possessive clitics in that the latter are theta-marked, and as such they bear interpretable features of referentiality. This is formally expressed by a richer syntactic structure of genitive clitics, which includes a higher functional layer, lacking in third-person accusative clitics. This difference can be shown to be responsible for the unavailability of clitic-doubling in the nominal domain. $^{4,5}$

(1) ??To vivlio tu tu-Jani the book his the-gen Jani-gen

"John's book"

Further evidence for the differences between genitive clitics in DPs and accusative clitics in the verbal domain can be found in idioms where accusative (but not genitive) clitics are extensively used nonreferentially (cf. Bibis \&

\footnotetext{
${ }^{3}$ An anonymous reviewer points out that the difference between first-/second-person and third-person clitics may not reside in the interpretability of the [person] feature, arguably unavailable in the latter case. Instead, it could be that the search for an appropriate referent is larger with third-person clitics as opposed to first- and second-person, where the options are restricted to speaker and hearer, respectively. Although this observation is correct, we do not think it plausible for the following reasons: First, it should extend to third-person strong pronouns as well, although evidence for the dissociation between first-/second- and third-person strong pronouns is not found in SLI data (cf. Tsimpli \& Stavrakaki, 1999). In addition, we maintain that the fact that the referent is unambiguously defined sententially in the case of first- and second-person pronominals, clitics or strong forms, is precisely due to the [person] specification in the grammar. Reference-assignment for third-person pronominals is, we assume, in the domain of pragmatic processing, that is, post-LF (Sperber \& Wilson, 1995). Finally, the underspecification of the [person] feature in third-person forms allows them to not refer at all, that is, to be expletives (see examples in (2)).

${ }^{4}$ It is possible in certain cases to double the genitive clitic with a full DP when the referent is ambiguous:

(i) Context: I sizitisi anamesa ston Petro ke sto Jani dhen katelikse puthena. The discussion between Petro and Jani didn't reach a conclusion. To lathos tu tu Jani itan oti ... The mistake his the-gen Jani was that...

In such cases the DP disambiguates the reference of the clitic. It seems that even this possibility is restricted to genitive clitics that are not possessors. In accusative cliticdoubling structures, however, there doesn't seem to be an effect of disambiguation involved. If there is an interpretative effect of clitic-doubling it is possibly that of verbfocusing (Agouraki, 1993).

${ }^{5}$ The interpretability of the genitive clitic could also be due to a thematic feature, such as [poss]. We thank an anonymous reviewer for this suggestion.
} 


\section{Tsimpli and Mastropavlou}

Roberge, in press). Genitive clitics can also be found in idioms, but they always refer.

(2) a. Tin-patise.

her-acc-stepped-on

"He failed" (Lit: 'He stepped on her')

b. Pai kalja tu.

Go-3s better his

"He is hopeless / He died" (Lit. 'He goes to his better [state]')

c. Oute psilos ston korfo tu

not-even a flea on the chest his

"He is in trouble." (Lit.: 'Not even a flea on his chest')

With respect to the Greek article system, the definite article has been argued to host uninterpretable features of case and agreement but no specification for the interpretable feature of [definiteness]. The indefinite article is intrinsically marked for [-definiteness], and as a result it differs from the definite in that it bears this interpretable feature along with case and agreement (cf. Giannakidou \& Stavrou, 1999; Giusti, 1997; Karanasios, 1992; Panagiotidis, 2002; Stavrou, 1996, for cross-linguistic evidence). Consequences of this difference in featurespecification between the definite and the indefinite article are the following properties associated with the former but not the latter (Tsimpli \& Stavrakaki, 1999): nominalization of non-nominal phrases (e.g., clauses, adverbials) as in (3a); doubling of the determiner within the DP (referred to as "determinerspreading" in Marinis \& Panagiotidis, in press), as in (3b); its co-occurrence with the demonstrative as in (3c); or its use with proper names and generic subjects or objects, among other structures, as in (3d).

(3) a. To oti efije noris simeni polla. The that left-3s early means a lot. "That he left early means a lot."

b. To pedhi to kalo

The child the good

"The good child"

c. I Maria eftase.

The-nom Maria arrived

"Maria arrived."

d. Afto to vivlio

This the book

"This book"

Table 3 summarizes the properties of clitics and articles in Greek. 
Feature Interpretability in L2 Acquisition and SLI 149

Table 3. Properties of clitics and articles in Greek

\begin{tabular}{lll}
\hline Articles & Interpretable features & Uninterpretable features \\
\hline Definite & $\emptyset$ & [case], [agreement] \\
Indefinite & {$[$-definite] } & [case], [agreement] \\
\hline Accusative (VP-) Clitics & & \\
\hline $1^{\text {st }} 2^{\text {nd }}$ person & {$[+$ person] } & [case], [agreement] \\
$3^{\text {rd }}$ person & $\varnothing$ & [case], [agreement] \\
\hline Genitive (NP-) Clitics & {$[+$ person] } & [case], [agreement] \\
\hline
\end{tabular}

Finally, an important difference that has not been pointed out in the previous discussion concerns the domain in which clitics and determiners appear. Although both determiners and clitics are argued to be D elements, articles appear in the nominal domain, whereas clitics appear in the verbal domain. This difference is evidenced, among other things, in the locality of the agreement process in each case. The definite article agrees with the noun it introduces as a result of the two elements belonging to the same dependency - the noun is "cselected" by D - whereas clitics agree with their antecedent indirectly and via their representation on the verbal complex. This representation may involve an empty category in the thematic position of the object (Sportiche, 1996, 1999), which is co-indexed with the clitic and with the discourse antecedent for reference-assignment. The implication is that the process of agreement within the DP is the result of resumptive agreement features instantiated on all items that participate in the dependency (i.e., D, Adjective, Noun), whereas the "checking" of agreement on the clitic is in a functional head position within the verbal domain (Cardinaletti \& Starke, 1999).

An additional difference between clitics and determiners concerns the possibility of movement for clitics but not for determiners. In particular, whereas D is merged directly in the relevant position, clitics may be analyzed as being merged in AGR-O, light $\mathrm{v}$, or INFL (depending on the analysis adopted) or moved to these positions (Kayne, 1989, 1991; Manzini \& Savoia, 2002; Nash \& Rouveret, 2002; Sportiche, 1996). Adopting the movement analysis for clitics implies that an additional complexity factor is introduced. In previous work on clitics in SLI grammars, this increased computational complexity has been argued to account for the attested difference between clitics and determiners in Romance data (Bottari, Cipriani, Chilosi, \& Pfanner, 2001; Jakubowicz \& Nash, 2001; Jakubowicz, Nash, Rigaut, \& Gérard, 1998).

It should be pointed out, however, that Greek clitics differ from Romance clitics in a number of ways. The identity of the D system, including clitics and articles, in Greek involves sharing of case and agreement features, whereas in Italian (and French) only agreement features are shared (Roussou \& Tsimpli, in press). Although Romance clitics are marked for case, articles are not. Thus, Greek clitics and determiners share the same feature-bundle, and as such they are amenable to a feature-based analysis depending on LF-interpretability. In Romance languages, on the other hand, this analysis cannot be applied on the D system with both articles and clitics included. Furthermore, the availability of 


\section{Tsimpli and Mastropavlou}

clitic-doubling in Greek with object DPs introduced by the definite article, can be viewed as a consequence of the featural and categorial similarity between articles and clitics (cf. Alexiadou \& Anagnostopoulou, 2001). Romance languages, on the other hand, generally disallow clitic-doubling; Spanish cliticdoubling differs from Greek in that animacy constraints are operative and a prepositional marker $a$ is required (Zagona, 2002).

In addition, theoretically, the interpretability approach adopted here does not consider the Merge versus Move option for clitics as potentially giving rise to different predictions in relation to articles, which are assumed to merge in D. Assuming that only uninterpretable features may trigger movement, the uninterpretable features of Greek clitics and determiners are not expected to show a difference in this respect. On the other hand, if clitics are moved and not merged in their position, they are predicted to be more problematic than the definite article in SLI grammars, precisely due to this additional complexity factor (cf. Bottari, Chilosi, \& Pfanner, 1998; Bottari et al., 2001; Jakubowicz \& Nash, 2001; Leonard, Bortolini, Caselli, McGregor, \& Sabbadini, 1992). Even though this would be an option compatible but not predicted by our approach, we would like to keep the more restrictive option based on interpretability alone, instead of adding a derivational complexity factor, for the following two reasons. The first is theoretical: We assume that both SLI and L2 grammars are UG-constrained in that operations such as Merge, Move, and Attract are available and that the reason why deviant uses of morphosyntax are attested is the status of uninterpetable features in the lexicon and not any movement processes that they may involve. Thus, problems with movement are a consequence of problematic analysis of uninterpretable features and not a deficit in the operation itself. The second reason is empirical: It is not at all clear that postulated movement processes in the syntactic derivation are more "complex" especially if they are required for well-formedness. Moreover, it is unclear whether complexity in syntactic derivations is directly reflected in processing these structures (either in perception or in production). In other words, the assumption that movement is necessarily more complex in psycholinguistic terms than no-movement could depend on the status of the moved element (phrase or head), its role at LF and PF, and so on (Fodor \& Inoue, 2000).

\subsection{Uninterpretable Features in L2 and SLI Grammars}

The distinction between LF-interpretable and uninterpretable features can be argued to be responsible for learnability differences in language development. If we assume, following Chomsky (1995), that uninterpretable features are primarily involved in the syntactic derivation and play no role at the LFinterface, it follows that they are also responsible for parametric differences between languages. Furthermore, language acquisition is supposed to involve a process of parameter-setting, in that the learner has to analyze the input in terms of identifying the appropriate features that regulate syntactic derivations 
together with the value that each feature has in a specific syntactic context. In Minimalism, interpretable features do not trigger syntactic operations, never erase, and remain active at the level of LF.

Notice, however, that it is also possible to identify cross-linguistic differences that pertain to interpretable features. For example, discourse-related features such as topic or focus appear to be syntactically active in certain languages (like Hungarian or Greek) but not others (e.g., English). It could then be argued that the grammaticalization of a semantic feature may be parameterized so that in some but not all languages it affects derivations and is subject to syntactic constraints (Kiss, 1998).

If this is correct, then the learner should analyze the input in terms of both interpretable and uninterpretable features, and parameterization could be associated with either set. Thus, the difference between the two sets is restricted to their role at LF and does not extend to whether or not they participate in syntactic operations. We could then argue that the learnability status of interpretable and uninterpretable features differs precisely due to their respective presence or absence at LF. Interpretable features provide cues to the learner on the basis of their direct (or indirect) mapping with categories relevant to conceptual representations (which are arguably nonmodular, at least not in the Fodorian sense). On the other hand, uninterpretable features are represented in the language module and necessary for linguistic computations exclusively. The crucial distinction is drawn from the modular nature of "narrow syntax" as opposed to the nonmodular nature of the LF-interface (the "syntax-discourse interface"; Platzack, 1999; Sorace, 2000; Tsimpli et al., in press). The diagram in (4) schematizes the language system according to Minimalist assumptions (Chomsky, 1995, 2001).
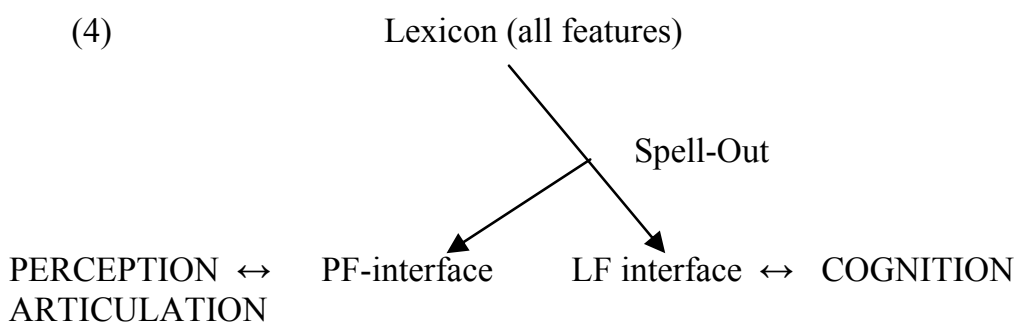

Semantic features, grammaticalized or not, are accessible by the interface either as part of the output of a syntactic representation (bottom-up) or as discourserelated features mapped onto LF top-down, that is, from the conceptual systems. It then follows as a logical possibility that any process of language development will have access to interpretable features, as their LF-related status ensures their mapping onto conceptual representations.

In earlier work (Hawkins, 2001; Hawkins \& Chan, 1997; Smith \& Tsimpli, $1995)$ in the theory referred to as the Failed Functional Features Hypothesis 


\section{Tsimpli and Mastropavlou}

(Hawkins \& Chan, 1997), it is suggested that formal features are subject to critical period constraints and therefore parameter-resetting in L2 acquisition is problematic. Contrary to full access theories (Lardiere, 2000; Schwartz \& Sprouse, 1996; Vainikka \& Young-Scholten, 1996; White, 1989, 2003, among others), the Failed Functional Features Hypothesis predicts persistent problems with parametric values of the L2 that differ from the native language. Assuming that parameters are not exclusively associated with uninterpretable features, however, this claim requires a reformulation along the lines of the distinction based on interpretability. In Tsimpli (2003), the hypothesis is that uninterpretable features are inaccessible to L2 learners due to the critical period, whereas interpretable features are always accessible, for the reasons outlined earlier, in relation to their representation at LF and its nonmodular status. This distinction makes L2 acquisition different from L1 due to the fact that L1 learners have access to both sets of features from an early stage. ${ }^{6,7}$

With respect to the L2 acquisition of D elements in Greek L2, it is then predicted that there should be a distinct pattern of development that separates the definite article and the third-person clitic on one hand, from the indefinite article and first-/second-person and genitive (possessive) clitics, on the other. The hypothesis is that despite the similarities expected due to these elements being members of the same paradigm, their feature-specification distinguishes them in terms of interpretability. Therefore, the definite article and the third-person accusative clitic should be more problematic for L2 learners than the other elements. In the data presented in this chapter, clitics and determiners in child

\footnotetext{
${ }^{6}$ In Tsimpli (in press) it is argued that focusing, an LF-related structure, is acquired earlier than the inflectional domain. This is evident only in the first stage of L1 acquisition and is rapidly followed by the emergence of inflectional features, clitics, and determiners.

7 An anonymous reviewer raises the question regarding L2 acquisition of V-to-I, (abstract) case, and other uninterpretable features. Specifically, if these features are inaccessible to the L2 learner, then none of these features and processes could be acquired in L2. This would indeed be a very strong claim and, at the same time, easily falsifiable empirically.

In this chapter we have opted to exemplify uninterpretability using the article and the third-person clitic, which are assumed to be clusters of uninterpetable features only. We would claim that if interpretable features are also specified on a lexical item, acquisition should be facilitated. The reason is that the learner will proceed using the interpretable feature as a cue, thus establishing at least optional use of the item in question. The uninterpretable features will remain problematic and will be acquired later, either in context-specific patterns (e.g., first in interrogatives, then in relatives, etc.) or learned. For example, assuming that wh-phrases have an interpretable (quantificational) feature and an uninterpretable feature that establishes agreement with the $\mathrm{C}$ head, and according to the interpretability theory adopted here, the interpretable feature of the whword will be the cue to acquisition; uninterpretable features regulating language-specific (i.e., parameterized) wh-options such as movement and resumptive strategies will remain problematic.
} 
and adult Greek L2 data are analyzed. The comparison between children and adult L2 learners aims to identify a possible locus of difference in their performance on these problematic items in order to shed some light on the age factor in L2 acquisition.

Turning now to SLI grammars, the hypothesis that uninterpretable features are problematic compared to interpretable ones has also been put forward on the basis of SLI performance on clitics and articles as well as inflectional features of tense and agreement (Tsimpli, 2001; Tsimpli \& Stavrakaki, 1999). In these studies, it is shown that third-person clitics and the definite article are more problematic for Greek SLI children compared to first-/second-person clitics, possessive clitics, and the indefinite article. Similar results have been obtained by further studies on Greek SLI: Definite articles have appeared to be omitted significantly more often than indefinite articles, whereas case marking on definite articles seemed to be affected by SLI in contrast with gender and number marking, a fact that can also be attributed to the lack of interpretability of the case feature (Mastropavlou \& Marinis, 2002). Moreover, it has been observed that the performance of SLI children in the production of possessive clitics is clearly better than their performance in object clitics (Mastropavlou, 2003). Additionally, the presence of object clitics in active sentences, coordinated structures and object-gap relatives has been shown to inhibit sentence comprehension by SLI children (Stavrakaki, 2000). This is accounted for on the assumption that object clitics are clusters of uninterpretable features that are problematic for SLI grammars (Stavrakaki, 2000). Finally, in Tsimpli and Stavrakaki (1999) and Tsimpli (2001), tense and agreement do not present the same pattern of difficulty in Greek SLI as in the SLI studies from German or English (Clahsen, Bartke, \& Gollner, 1997; Rice \& Wexler, 1996; Rice, Wexler, $\&$ Cleave, 1995). With respect to subject-verb agreement, the cross-linguistic difference found is attributed to the fact that Greek, but not English or German, is a null subject language. Thus, agreement could be analyzed as having referential [person] features and acting as a pronominal (Alexiadou \& Anagnostopoulou, 1998; Rizzi, 1982). With regard to Tense, Greek marks Tense distinctions primarily phonologically, by stress shift to the antepenultimate syllable. Their salience in the input is therefore high in that both phonological and morphological information is included. The difference between German/English tense marking and Greek is then attributed to the phonological dimension of Tense realization. Overall, the interpretability approach can (a) accommodate language-specific differences found on apparently similar lexical items or features (e.g., Romance and Greek clitics and determiners, Inflection) and (b) predict the domain of difficulty in SLI grammars based on the status of these features at the interface (cf. Jakubowicz \& Roulet, this vol.).

In this chapter, new data from six Greek SLI children of two different age groups are presented, concentrating on their use of possessive genitive and accusative clitics, as well as of the definite and the indefinite article. It is shown that three of the children appear to show a less developed stage of grammatical 


\section{Tsimpli and Mastropavlou}

development compared to the other three, who perform significantly better. Although the observed development appears to affect the third-person clitic and the definite article, as predicted by the hypothesis based on interpretability distinctions, it is shown that performance in the more advanced SLI children has improved despite the fact that all six of them have had, at the time of data collection, minimal speech therapy. These results support the interpretability hypothesis for learnability of grammatical features but, at the same time, questions the status of the deviance from normal L1 acquisition as showing a delay rather than a deficit (cf. Clahsen, 1989, 1991; Gopnik, 1990; Gopnik \& Crago, 1991; Rice et al., 1995; Rice \& Wexler, 1996; van der Lely, 1994, 2003).

It becomes apparent that the comparison between L2 and SLI grammars is based on the assumed dissociation between interpretable and uninterpretable features in learnability terms. Specifically, interpretable features are arguably accessible in all processes of language development, whereas uninterpretable features become inaccessible either due to constraints related to the critical period hypothesis or to the incomplete or deficient analysis of L1 input.

The obvious question with regard to the notion of inaccessibility of uninterpretable features is whether the features are altogether unavailable and therefore impossible for L2 learners or SLI children to analyze in the input or whether these features are part of the linguistic lexicon, but due to uninterpretability, they cannot be identified in the input in terms of category and value. As far as L2 learners are concerned, it is clear that the L1 activates interpretable and uninterpretable features. Inaccessibility in this case refers to the problems L2 learners have in analyzing the L2 input by making use of uninterpretable features that are not shared by their native language or which are included in the L1 but with different specification. For example, in the present study the native language of the L2 learners has case and agreement features active in the nominal and the verbal paradigm, but not on a determiner system. Moreover, pronouns are available but not of the clitic type. The problem for these learners, then, is the target analysis of Greek clitics and determiners as D elements bearing uninterpretable features. Targetlike use of case and agreement morphology is predicted, however, as development of the morphological paradigm is not blocked: Syntax and morphology are distinct components, and as such they can dissociate in language development or impairment (Lardiere, 2000; Prevost \& White, 2000; Smith \& Tsimpli, 1995). Therefore, the problem lies in the mapping between overt morphology and abstract feature specification, when the features involved are uninterpretable. Determiner use in L2 Greek is predicted to develop, although the set of obligatory contexts will differ from that of the native speaker, due to the nontarget feature-specification of determiners in the L2 lexicon. In order to constrain optional use of determiners in the L2, the learner imposes interpretable features such as [referentiality] or [specificity] on the Greek article. Thus, L2 use improves considerably but does not become nativelike. 
Turning to SLI grammars, the notion of (in)accessibility of uninterpretable features refers to problems in the appropriate analysis of the input, due to the incomplete or deficient representation of the functional lexicon. The developmental pattern in SLI grammars differs from that of normal L1 acquisition primarily in terms of the relation in the development of morphology and syntax. In normally developing L1 grammars, the mapping between abstract features and morphological realization is fast and automatic given that acquisition involves the identification of the abstract formal features (interpretable and uninterpretable) together with the values they may have, from the input. In SLI, analysis of the input in terms of identification of formal uninterpretable features and values is incomplete. The SLI grammar is then predicted to show optionality in the use of overt morphology due to the problems in accessing a deficient or incomplete set of features in the lexicon.

Notice that although the domain of the grammar, that is, the uninterpretable set of formal features, is the locus of the problem in both L2 and SLI development, the underlying cause is different in each case. In particular, although we can remain agnostic about SLI being associated with the processor rather than the grammar per se (see articles in Levy \& Schaeffer, 2003) or the question of a grammatical deficit versus a delay in language development, the cause appears to be genetically related and exhibits a pattern of properties and dissociations from other cognitive abilities that are intact (Bishop \& Adams, 1990; Gopnik \& Crago, 1991; van der Lely, 1996). Thus, SLI children exhibit delays or disorders in the acquisition of grammar in the absence of hearing loss, mental retardation, motor-articulatory impairment, or psychoemotional disorders (Bloom \& Lahey, 1978; Clahsen, 1989). On the other hand, although L2 acquisition shows age-related effects (Johnson \& Newport, 1989, 1991), there are considerable individual differences among L2 learners; moreover, there are L2 learners who can attain near-native ability in the second language (Birdsong, 1992; Coppieters, 1987; White \& Genesee, 1996). It is unlikely that such differences in L2 performance could be shown to have a neurological correlate or a dissociation from, or an intrinsic link with, other cognitive abilities. Thus, although SLI and L2 performance on uninterpretable features may show a similar pattern, it would be difficult to attribute the similarities attested to a common underlying cause.

\subsection{Compensatory Strategies: The Role of Interpretable Features in Misanalyzed Input}

A recurrent theme in the literature of L2 acquisition is the question of the attested optionality or variability in L2 grammars (Eubank, 1994; Parodi \& Tsimpli, in press; Sorace, 1999). Specifically, the question is whether optionality is a property that characterizes L2 grammars even at an advanced stage or whether it is a property of developing grammars only. In view of the theory presented here, which maintains that uninterpretable features are inaccessible to 


\section{Tsimpli and Mastropavlou}

L2 learners, it follows that the relevant input (i.e., third-person clitics and the definite article) will fail to be analyzed in a target way by the L2 grammar. As a result, L2 learners will use the relevant items optionally, at best.

It could be argued, however, that advanced L2 grammars disallow optionality, on the grounds that they are UG-constrained grammars, and real optionality can, at best, be a property of developing grammars (Eubank, 1994; Parodi \& Tsimpli, in press; Sorace, 1999). ${ }^{8}$ On this assumption, advanced L2 grammars that appear to use aspects of the morphosyntax optionally do so only superficially: The grammar has nonoptional representations that are not targetlike due to the feature-specification incorrectly assigned to the L2 input. Oversimplifying the developmental process, we could identify two stages in L2 acquisition. In the first one, the L2 grammar fails to analyze the input and, as a result, exhibits true optionality in the use of the relevant items. ${ }^{9}$ The second stage involves misanalysis of the input, that is, nontarget feature specification which, nevertheless, constrains the use of the L2 items. The features involved during this stage are interpretable features which are assigned by the learner to the problematic items in order to regularize their distribution.

An example of this type of misanalysis is presented in Tsimpli $(1997,2003)$ from English L2 data of native speakers of Greek. The phenomenon tested is the resumptive strategy found in Greek interrogatives. It consists in the use of subject-verb agreement features specified on the verb form or object clitics, respectively. The possibility of using clitics and agreement resumptively is based on the uninterpretability of the features involved, namely agreement and Case. Subject-verb agreement and object clitics used resumptively in Greek interrogatives spell out the features of the subject or object wh-phrase in sentence-initial position. The misanalysis attested in the English L2 of Greek speakers is evidenced by the use of subject and object English pronouns as resumptive elements, illustrated by the examples in (5).

\footnotetext{
${ }^{8}$ An anonymous reviewer points out that cases of true optionality are also found in native grammars; for example, the option of a null or an overt complementizer in English embedded declaratives. We agree with the reviewer that assuming different numerations does not solve the problem of this type of optionality, where abstract feature-specification seems to be identical. We acknowledge this fact as a problem. Possibly, these cases of optionality that involve phonological variants of the same feature-complex could be shifted to interface levels. The criterion for this "shifting" of optionality to interface levels would be whether the two options are related to preference rather than grammaticality differences. This could also extend to variation found in the use of overt subject pronouns in null subject languages when discourse-related features, such as emphasis or topic-shift, are involved (Sorace, 2000; Tsimpli et al., in press). Crucially, however, the grammar (i.e., narrow syntax) provides the constraints on the syntactic contexts in which this optionality is possible. Thus, a null complementizer is not an option in noun complement clauses.

${ }^{9}$ There is an earlier stage where omission, rather than random use, is attested.
} 
Feature Interpretability in L2 Acquisition and SLI 157

(5) a. *Who / Which student did you think that he failed the exams?

b. *What / Which rumor did you say that Mary has spread it?

In these L2 studies (Tsimpli 1997, 2003), ungrammatical sentences such as $(5 \mathrm{a} \& \mathrm{~b})$ are judged grammatical even by advanced Greek learners of English. Crucially, acceptability of resumptive pronouns increases if the pronoun is inanimate. Given that [animacy] is not an L1 feature that regulates resumptive uses of pronouns, the fact that it appears to affect L2 judgments indicates a restructuring of the L2 grammar in a UG-based fashion: The parametric choice of resumption is maintained, but the L2 input has led the learner to impose a constraint on resumption rather than apply the resumptive strategy randomly. This is possible, due to the interpretability of the [animacy] feature, and necessary, due to the general constraint on optionality in advanced L2 grammars.

Turning to SLI grammars, it has been argued that evidence for compensatory strategies is also found in SLI data (Paradis \& Gopnik, 1994, 1997). More specifically, segmental and prosodic anomalies in the production of plural number by English SLI subjects have been attributed to a morphological deficit, namely the absence of [+/-plural], and have been characterized as "compensatory means" of building plurals (Goad, 1998). Likewise, in Tsimpli and Stavrakaki (1999), nontarget use of emphatic stress on the verb's initial syllable in wh-questions is used as a compensatory strategy for the absence of what. Notice, however, that in this case, the omitted element includes an interpretable feature (i.e., the quantificational feature of [wh]) which, according to the analysis proposed in Tsimpli and Stavrakaki, is the motivation for the compensatory strategy adopted by the SLI grammar. In other words, the difference between the SLI and the advanced L2 grammar in this respect is that in SLI, compensation is led by the deficient production of an interpretable feature, whereas in L2, compensation is due to the persistent inability of the grammar to analyze the input in a targetlike fashion.

Assuming that misanalysis is indeed a possibility in advanced developing grammars, an analysis of contexts where the definite article and the third-person clitic are used or omitted will be conducted in order to identify the nontarget interpretable features that may regulate the distribution of those items in the L2 grammars.

\section{SUBJECTS}

\subsection{Adult L2 learners: Russian and Turkish L1s}

The L2 data come from six adult early bilinguals in Turkish and Russian (age range: $27-46$ years). They immigrated to Greece in the period between July 1992 and March 1993 and, at the time of testing, had no knowledge of Greek. 


\section{Tsimpli and Mastropavlou}

L2 acquisition of Greek did not involve any instruction or other form of structured input. All subjects have been working in Greek-speaking environments since the first year of their residence in the country and have been using the language on an everyday basis. Moreover, all of the subjects have had everyday contact with Greek, not only in their work environment but also at home. This is primarily due to the fact that all of these subjects have children who are dominant in Greek and prefer using Greek at home over their parents' native languages.

The data were collected in July-August 2001 and come from spoken production in the context of a 45-minute oral interview. Given that the length of stay in the country was over 8 years for these L2 learners, it is possible that their grammatical knowledge in L2 has reached a final state. The interview began with questions related to the subjects' use of their native languages and Greek L2, as well as biographical information concerning their education, age, and occupation.

Table 4. Subjects and their arrival ages

\begin{tabular}{lc}
\hline Subjects & Age at arrival \\
\hline Marika, 30 & 22 \\
Midhia, 35 & 28 \\
Afroditi, 34 & 26 \\
Zanna, 40 & 31 \\
Lamara, 46 & 35 \\
Toma, 27 & 18 \\
\hline
\end{tabular}

With respect to the syntactic features examined in this study, note that both Russian and Turkish share the property of lacking an article system:

(7) ja pisal pis'mo

I was-writing letter

"I was writing a/the letter."

Unambiguous definite reference can be expressed by the use of the demonstrative introducing a noun, whereas unambiguous indefinite reference can be expressed by the use of the numeral 'one' which can, in some contexts, be used as a marker of indefiniteness (examples from Zlatić, 1998).

(8) a. eti milye d evushki

this-N.F.PL nice-Nom.F.PL. girls

"these nice girls"

b. milye eti devushki. 
(9) Speaker A: što u tebjá tám? (=what have you got there?)

Speaker B: Ničevó, adná stàraja kníga

nothing, one old book

"Nothing special, an old book."

As for pronominal objects, Turkish lacks pronominal clitics and weak pronouns, whereas Russian has strong and weak pronouns but not clitics (Franks \& King, 2000; Halpern \& Fontana, 1993).

Notice the crucial fact that both languages allow null objects with specific reference (Russian examples from Motsiou, personal communication, March 15, 2004; Turkish from Kornfilt, 1997):

(10)a. Speaker A: Ty kupil knigu?

you bought book

"Did you buy a/the book?"

Speaker B: (Da), kupil. OR B: Niet nie kupil

yes bought-1s no not bought-1s

b. Ja ejo kupil.

"I bought it." "I didn't buy it."

I her bought-1s

"I bought it."

(11) (Context: Speaker looking for his glasses)

bul-du-m!

find-Past-1s

"I found (them)!"

Notice that the possibility of including an overt object pronoun is available, as shown by the Russian example in (10b). However, this utterance is not acceptable as a response to Speaker A's question in (10a), which favors a null object. ${ }^{10}$

In the same context, Greek disallows null objects and requires a clitic pronoun in the object position as shown by the examples in (12).
(12)a. Speaker A: Pu ine i ombrela mu? 'Where is the umbrella my'
Speaker B: *(Tin)-filaksa.
Her-put-away-1s
"I put it away."

\footnotetext{
${ }^{10}$ Null objects with specific reference can be first-, second-, or third-person pronouns although constraints based on features such as [+human], [+animate] regulate speakers' preferences to some extent (see Kowaluk, 2001; McShane, 2002, for Slavic languages, among others).
} 
160 Tsimpli and Mastropavlou

\author{
b. *(Ta)-vrika. \\ Them-found-1s \\ "I found them."
}

We can then summarize the differences in the D system between the L1s and Greek (L2) as in Table 5.

Table 5. D elements in L1 and L2

\begin{tabular}{lll}
\multicolumn{3}{c}{ Table 5. D elements in L1 and L2 } \\
\hline Weak pronouns or Clitics & weak pronoun & Greek \\
Null object & $\sqrt{ }$ & clitic \\
Articles & $\times$ & $\times$ \\
\hline
\end{tabular}

On the basis of the contrast exhibited in examples (10)-(12), it is predicted that object clitics will be omitted in obligatory contexts by these L2 learners as a result of L1 transfer. More interesting, however, although object omission is possible for all person and number features in the L1s, the interpretability distinction put forward in section 2 predicts that these L2 learners will omit third person accusative clitics more frequently than first- or second-person object clitics. Similarly, third-person accusative clitics will be omitted more frequently than third-person genitive possessive clitics. It is in this respect that interpretability can be shown to play a crucial role in learnability.

Determiner omission is also expected due to L1 transfer. Nevertheless, omission rates of the definite article should be higher than those of the indefinite. Similarly with the dissociation predicted for first-/second- versus third-person clitics, more accurate use of the indefinite article compared to the definite cannot be related to L1 effects but to the role of interpretability in developing L2 grammars. Moreover, if misanalysis of the definite article is indeed associated with some interpretable feature in the L2 data, differences in the omission rate, which depend on the nature of the syntactic context, are predicted to be found.

\title{
3.2. Child L2 Learners: Turkish L1
}

Oral production data from 10 Turkish-speaking children (age range: 8-12 years) collected in the period between March and June 2003 are presented (Mavridou, 2003). The children were born and are being reared in Greece by Turkishspeaking parents. They live in Iazmos Rodopis, an area in northern Greece with a large Turkish-speaking community. The children attend a minority school where some subjects are taught in Greek and some in Turkish. Given that the home language but also the community language is primarily Turkish, these children are not bilingual. Instead, Greek is the language associated with schooling and the media. By the age of 6 , when schooling begins, children in this area have minimal knowledge of Greek. As shown in Table 6, children of 
the same age may belong to different school grades, depending on their knowledge of Greek when they are admitted to the primary school.

\begin{tabular}{ll}
\multicolumn{2}{c}{ Table 6. Information on the Child L2 groups } \\
\hline \multicolumn{1}{c}{ Group 1 } & \multicolumn{1}{c}{ Group 2 } \\
\hline Mutlu 8 yrs- $2^{\text {nd }}$ grade & Önder $11 \mathrm{yrs}-4^{\text {th }}$ grade \\
Elif $9 \mathrm{yrs}-3^{\text {rd }}$ grade & Gökhan $11 \mathrm{yrs}-4^{\text {th }}$ grade \\
Embrul $9 \mathrm{yrs}-2^{\text {nd }}$ grade & Ismail $11 \mathrm{yrs}-5^{\text {th }}$ grade \\
Feride $9 \mathrm{yrs}-3^{\text {rd }}$ grade & Melek $11 \mathrm{yrs}-4^{\text {th }}$ grade \\
Fatme A. $9 \mathrm{yrs}-3^{\text {rd }}$ grade & Fatme B. $12 \mathrm{yrs}-6^{\text {th }}$ grade \\
\hline
\end{tabular}

The children are divided in two age groups (Group 1, age range: 8-9 yrs and Group 2, age range: 11-12 yrs) of five children each. The data were collected in the context of an informal interview with the presentation of five series of pictures, each forming a story that the child was asked to narrate.

The predictions with respect to the acquisition of Greek articles and clitics are presented in the previous section. The question as to whether the child-adult difference will play a role in language development remains open. It is expected, however, that child learners will fare better than adult learners given results from previous studies (Haznedar \& Schwartz, 1997; Lakshmanan, 1994; Schwartz, 2002).

\subsection{SLI Children}

Oral (spontaneous) production data from six SLI children are presented. They were diagnosed as SLI ${ }^{11}$ by the diagnostic unit of the Centre of Common Mental Health in Kesariani, Athens. ${ }^{12}$ They meet the criteria for SLI in that they all exhibit a delay in grammatical development with no parallel hearing loss, mental retardation, motor-articulatory impairment, or psychoemotional disorders (cf. Bloom \& Lahey, 1978; Clahsen, 1989). All children are Greek monolinguals and, at the time of data collection, had just started attending speech therapy sessions at the center where they had been diagnosed. They attended two $1 \frac{1 / 2-}{2}$ hour therapy sessions a week, and they were divided by the speech therapists into two groups, according to their age and general linguistic and mental

\footnotetext{
${ }^{11}$ The children that are diagnosed as SLI in the center are not usually subcategorized into grammatical or semantic SLI. However, the children that participated in the study were carefully selected so that their deficit mainly involved grammatical development, accompanied with less severe phonological and semantic problems.

${ }^{12}$ It is important to note that the data collection would not have been possible without the valuable help of the speech therapist responsible for the SLI children, Mr. Maria Vlassopoulou.
} 


\section{Tsimpli and Mastropavlou}

development. Three children from each group were selected. For the purposes of the present study, two age groups are presented, as in (7).

Table 7. Information on the SLI groups

\begin{tabular}{ll}
\hline Group 1 & Group 2 \\
\hline C.K. $-4 ; 6$ & K.K. $-6 ; 2$ \\
S.M. $-4 ; 4$ & N.P. $-5 ; 6$ \\
L.V. $-4 ; 0$ & S.L. $-5 ; 9$ \\
\hline
\end{tabular}

Data collection took place between October 2002 and January 2003 in 30- to 40minute sessions. Each child was interviewed individually, and the data were tape-recorded.

\section{RESULTS}

In what follows, the results from adult L2 learners, child L2 learners, and SLI children are presented separately. Comparisons will be drawn in the Discussion section (section 5).

\subsection{Adult L2 Data}

Let us first consider the article system and, in particular, the use and omission rates of $\mathrm{D}$ elements in the total number of obligatory contexts (see Table 8).

Table 8. Use and omission of definite and indefinite Ds in obligatory contexts

\begin{tabular}{lllll}
\hline & DEFINITES & \multicolumn{3}{l}{ INDEFINITES } \\
\hline SUBJECTS & Use & Omission & Use & Omission \\
\hline Marika & $42-78 \%$ & $12-22 \%$ & $39-90 \%$ & $4-10 \%$ \\
Midhia & $30-57 \%$ & $23-43 \%$ & $55-96 \%$ & $2-4 \%$ \\
Afroditi & $78-61 \%$ & $49-39 \%$ & $38-95 \%$ & $2-5 \%$ \\
Zanna & $37-53 \%$ & $33-47 \%$ & $33-85 \%$ & $6-15 \%$ \\
Lamara & $21-10 \%$ & $185-90 \%$ & $121-100 \%$ & 0 \\
Toma & $121-75 \%$ & $40-25 \%$ & $53-93 \%$ & $4-7 \%$ \\
Total: & $329-49 \%$ & $342-51 \%$ & $339-95 \%$ & $18-5 \%$ \\
\hline
\end{tabular}

As can be seen from the group results, but also the individual results, use of the definite article fluctuates considerably more than use of the indefinite. It is particularly striking that none of the subjects approaches mastery of the definite 
article, assuming mastery to be defined on the basis of $90 \%$ use, but all but one subject (namely Zanna) are successful in indefinite contexts.

The difference between the use / omission of the definite as opposed to the indefinite $\mathrm{D}$ is significant for all subjects except for Marika (S1). [Midhia $\left(\chi_{(1,}^{2}\right.$ $\left.{ }_{109)}=24.88, \mathrm{p}=.000\right)$, Afroditi $\left(\chi_{(1,160)}^{2}=16.17, \mathrm{p}=.000\right)$, Zanna $\left(\chi_{(1,108)}^{2}=\right.$ $10.99, \mathrm{p}=.001)$, Lamara $\left(\chi_{(1,326)}^{2}=250,236 \mathrm{p}=.000(327)\right)$ and Toma $\left(\chi_{(1,217)}^{2}\right.$ $=8,305, \mathrm{p}=.004)$. Furthermore, the difference is significant in the total results from definite and indefinite contexts: $\left.\chi_{(1,1027)}^{2}=215,991, \mathrm{p}=.000\right] .{ }^{13}$

The examples in (13) illustrate definite article omission in the adult L2 data. The items in parentheses are not produced by the L2 speaker.

(13)a. *(tin) eliniki glossa *(tin) ixa ap'ti tileorasi... (Afroditi) (the) greek language (her)-had-1s from the television

"I had the Greek language from television..."

b. *(o) andras mu pote den ithele na mini edho... (the) husband my never not wanted sub. stay-3s here "My husband never wanted to stay here..."

Table 9. Use and omission of clitics in obligatory contexts

\begin{tabular}{|c|c|c|c|c|}
\hline & \multicolumn{2}{|c|}{$3^{\mathrm{RD}}$ PERSON CLITIC } & \multicolumn{2}{|c|}{$1^{\mathrm{ST}} / 2^{\mathrm{ND}}$ PERSON CLITICS } \\
\hline SUBJECTS & Use & Omission & Use & Omission \\
\hline Marika & $12-75 \%$ & $4-25 \%$ & $38-100 \% *$ & 0 \\
\hline Midhia & $16-80 \%$ & $7-20 \%$ & $13-93 \%$ & $1-7 \%$ \\
\hline Afroditi & $19-42 \%$ & $26-58 \%$ & $4-100 \% *$ & 0 \\
\hline Zanna & $7-10 \%$ & $65-90 \%$ & $17-85 \% *$ & $3-15 \%$ \\
\hline Lamara & $5-16 \%$ & $27-84 \%$ & $5-29 \%$ & $12-71 \%$ \\
\hline Toma & $38-65.5 \%$ & $20-34.5 \%$ & $37-88 \% *$ & $5-12 \%$ \\
\hline \multirow[t]{2}{*}{ Total: } & $87-37 \%$ & $149-63 \%$ & $104-83 \%$ & $21-17 \%$ \\
\hline & \multicolumn{4}{|c|}{ POSSESSIVE CLITICS } \\
\hline SUBJECTS & Use & Omission & & \\
\hline Marika & $5-83 \%$ & $1-17 \%$ & & \\
\hline Midhia & $9-100 \%$ & 0 & & \\
\hline Afroditi & $11-100 \% *$ & 0 & & \\
\hline Zanna & $2-100 \% *$ & 0 & & \\
\hline Lamara & $4-67 \% *$ & $2-33 \%$ & & \\
\hline Toma & $13-81 \%$ & $3-19 \%$ & & \\
\hline Total: & $44-88 \%$ & $6-12 \%$ & & \\
\hline
\end{tabular}

* indicates that there is a sig. difference in the use/omission of the clitics in question and the third-person clitic.

As in the case of the comparison between the definite and the indefinite article, note that first-/second-person clitics and possessive clitics are over $80 \%$ in use, in total, whereas third-person accusative clitics are remarkably lower, that is,

${ }^{13}$ We are grateful to Maria Dimitrakopoulou for her invaluable help with the statistical analysis of the data. 


\section{Tsimpli and Mastropavlou}

$37 \% .{ }^{14}$ The difference between the use/omission of the third-person accusative clitic compared to the first-/second-person clitics is significant in the data of four subjects: Marika $\left(\chi_{(1,53)}^{2}=10.26, \mathrm{p}=.001\right)$, Afroditi $\left(\chi_{(1,48)}^{2}=4.92, \mathrm{p}=.026\right)$, Zanna $\left(\chi_{(1,9 l)}^{2}=46.00, \mathrm{p}=.000\right)$, Toma $\left(\chi_{(1,99)}^{2}=6.62, \mathrm{p}=.010\right)$. In the data from the two remaining subjects, Midhia and Lamara, the difference is nonsignificant. In the group results, the difference is also significant $\left(\chi_{(1,380)}^{2}=\right.$ $71.47, \mathrm{p}=.000)$.

(14)a. ...ithela na *(ta) matho, jafto ta ematha. (Toma) wanted-1s sub. (them) learn-1s for-this them learned-1s "I wanted to learn it [Greek], that's why I learned it."

b. .....ke*(to) exume akomi eki, dhen *(to) pulisame *(to) spiti. ... and (it) have-1p still there not (it) sold-1p (the) house "...and we still have it there, we haven't sold the house."

Furthermore, the difference between third-person accusative clitics (VP-clitic) and third-person possessive clitics (NP-clitics) is significant for three of the subjects: Afroditi $\left(\chi_{(1,55)}^{2}=11.86, \mathrm{p}=.001\right)$, Zanna $\left(\chi_{(1,73)}^{2}=14.85, \mathrm{p}=.000\right)$ and Lamara $\left(\chi_{(1,37)}^{2}=7.28, \mathrm{p}=.007\right)$ as well as for the whole group $\left(\chi_{(1,295)}^{2}=\right.$ $94.90, \mathrm{p}=.000)$.

Figure 1 illustrates the use of the definite article compared to the thirdperson accusative clitic. The production of clitics differs significantly from the production of the definitie article for two of the subjects, Afroditi $\left(\chi^{2}(1,171)=\right.$ $4,978, \mathrm{p}=.026)$ and Zanna $\left(\chi_{(1,14 I)}^{2}=30.88, \mathrm{p}=.000\right)$, whereas no siginificant difference was found in the performance of the remaining four subjects.

To summarize the adult L2 data, overall, the predictions are borne out: Within the paradigms of articles and clitics, the definite article and the thirdperson appear to be problematic compared to the indefinite article, first-/secondperson clitics, and the genitive (possessive) clitics. The asymmetry found within paradigms indicates that the acquisition of clitics and determiners does not proceed in a straightforward way for all members of the D system. In the theory presented here, the feature-specification of the definite $\mathrm{D}$ and the third-person VP-clitic set these two items apart. Specifically, the uninterpretable feature-set that characterizes these two items seems to provide the right basis for accounting for the asymmetrical pattern of performance observed.

\footnotetext{
${ }^{14}$ Which type of clitic is omitted is determined by context, as this is spontaneous spoken production data. Furthermore, in response to a question by an anonymous reviewer, it should be noted that Greek clitics can only be pronominal and not reflexive. Reflexivisation involves the use of voice morphology suffixed on the verb (see also footnote 2).
} 
Feature Interpretability in L2 Acquisition and SLI 165

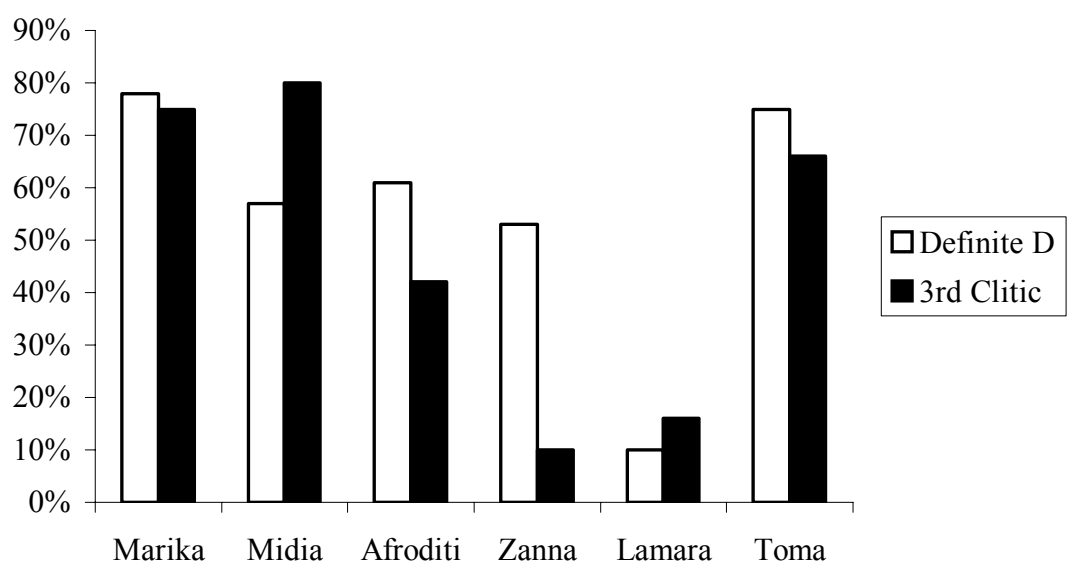

Figure 1. Comparison between use of definite D and third-person VP-clitic

\subsection{Child L2 Data}

As in the presentation of the adult L2 data, we first consider the use and omission pattern of $\mathrm{D}$ in definite and indefinite contexts (Table 10).

Table 10. Use and omission of definite and indefinite Ds in obligatory contexts

\begin{tabular}{lllll}
\hline SUBJECTS & DEFINITES & \multicolumn{3}{l}{ INDEFINITES } \\
\hline GROUP 1 & Use & Omission & Use & Omission \\
\hline Mutlu & $3-24 \%$ & $10-76 \%$ & $24-100 \%$ & $0-0 \%$ \\
Elif & $35-47 \%$ & $40-53 \%$ & $20-100 \%$ & $0-0 \%$ \\
Embrul & $55-89 \%$ & $7-11 \%$ & $6-86 \%$ & $1-14 \%$ \\
Feride & $15-54 \%$ & $13-46 \%$ & $14-74 \%$ & $5-26 \%$ \\
Fatme 1 & $26-67 \%$ & $13-33 \%$ & $8-80 \%$ & $2-20 \%$ \\
TOTAL & $134-62 \%$ & $83-38 \%$ & $72-90 \%$ & $8-10 \%$ \\
\hline GROUP 2 & & & & \\
\hline Önder & $28-90 \%$ & $3-10 \%$ & $9-100 \%$ & $0-0 \%$ \\
Gökhan & $48-86 \%$ & $8-14 \%$ & $6-75 \%$ & $2-25 \%$ \\
Ismail & $36-95 \%$ & $2-5 \%$ & $16-100 \%$ & $0-0 \%$ \\
Melek & $35-76 \%$ & $11-24 \%$ & $13-100 \%$ & $0-0 \%$ \\
Fatme 2 & $54-100 \%$ & $0-0 \%$ & $8-100 \%$ & $0-0 \%$ \\
TOTAL & $201-89 \%$ & $24-11 \%$ & $52-96 \%$ & $2-4 \%$ \\
\hline
\end{tabular}

With the exception of Embrul, who uses the definite article considerably more than the other subjects of Group 1, there does not seem to be a lot of variation among other subjects in either group. Thus, the statistical analysis is performed on group results. The difference between the use/omission of the definite and the indefinite $\mathrm{D}$ is significant in Group $1\left(\chi_{(1,296)}^{2}=21.95, \mathrm{p}=.000\right)$ and 


\section{Tsimpli and Mastropavlou}

nonsignificant in Group 2. As shown in Table 10, indefinite contexts appear targetlike even in the younger group of subjects, whereas use of the definite article shows clear development giving rise to similar performance in definite and indefinite Ds in the older group.

$$
\begin{array}{lll}
\text { (15)a. afto * }(\mathrm{o}) \quad \text { dhaskalos grafi *(ston) } & \text { pinaka. } & \text { (Mutlu) } \\
\text { this (the-nom) teacher writes (on-the) } & \text { board } & \\
\text { "This teacher is writing on the board." } & \\
\text { b. ...ke edho fevji *(to) aeroplano } & \\
\text { and here leaves (the-nom) airplane } & \\
\text { "....and here the plane is leaving..." } &
\end{array}
$$

Turning to clitics, Table 11 presents the data from the third-person accusative clitics (VP-clitics) and possessive clitics (NP-clitics). ${ }^{15}$

Table 11. Use and Omission of VP- and NP-clitics in obligatory contexts

\begin{tabular}{lllll}
\hline SUBJECTS & \multicolumn{2}{l}{ THIRD-PERSON CLITIC } & \multicolumn{2}{l}{ POSSESSIVE CLITICS } \\
\hline GROUP 1 & Use & Omission & Use & Omission \\
\hline Mutlu & $0-0 \%$ & $0-0 \%$ & $0-0 \%$ & $4-100 \%$ \\
Elif & $3-30 \%$ & $7-70 \%$ & $1-8 \%$ & $11-92 \%$ \\
Embrul & $3-38 \%$ & $5-62 \%$ & $1-14 \%$ & $6-86 \%$ \\
Feride & $0-0 \%$ & $1-100 \%$ & $1-14 \%$ & $6-86 \%$ \\
Fatme 1 & $1-14 \%$ & $6-86 \%$ & $6-67 \%$ & $3-33 \%$ \\
Total & $7-27 \%$ & $19-73 \%$ & $9-23 \%$ & $30-77 \%$ \\
\hline GROUP 2 & & & & \\
\hline Önder & $3-60 \%$ & $2-40 \%$ & $10-83 \%$ & $2-17 \%$ \\
Gökhan & $3-37.5 \%$ & $5-61.5 \%$ & $8-100 \%$ & $0-0 \%$ \\
Ismail & $13-81 \%$ & $3-19 \%$ & $23-100 \%$ & $0-0 \%$ \\
Melek & $0-0 \%$ & $3-100 \%$ & $10-100 \%$ & $0-0 \%$ \\
Fatme 2 & $6-47 \%$ & $7-53 \%$ & $7-64 \%$ & $4-36 \%$ \\
ToTAL & $25-56 \%$ & $20-44 \%$ & $58-91 \%$ & $6-9 \%$ \\
\hline
\end{tabular}

Within-groups, the difference between accusative and possessive clitics is nonsignificant in Group 1 and significant in Group $2\left(\chi_{(1,108)}^{2}=17.89, \mathrm{p}=.000\right)$. Between-groups, the difference in the use of possessive clitics is also significant $\left(\chi_{(1,111)}^{2}=26.96, \mathrm{p}=.000\right)$.

$$
\begin{aligned}
& \text { (16)a. ...fakelos... ke meta *(to) vazi mesa... (Ismail) } \\
& \text { envelope....and then (it) puts-3s inside... } \\
& \text { "It's an envelope... and then he puts it [the letter] in..." }
\end{aligned}
$$

\footnotetext{
${ }^{15}$ In the child L2 data there are only two contexts for first- and second-person accusative clitics, and they have been excluded from the presentation. Thus, a comparison between first-/second- and third-person clitics could not be made due to the very small number of occurrences for the former set.
} 
Feature Interpretability in L2 Acquisition and SLI 167

b. ...ke meta pu agorasa ta paputsia, ${ }^{*}($ ta) foresa... (Embrul) and after than bought-1s the shoes (them) put-on-1s...

"... and after I bought the shoes, I put them on..."

Figures 2 and 3 show the pattern of use and omission of the definite article and the VP-clitic in each group of child L2 learners.

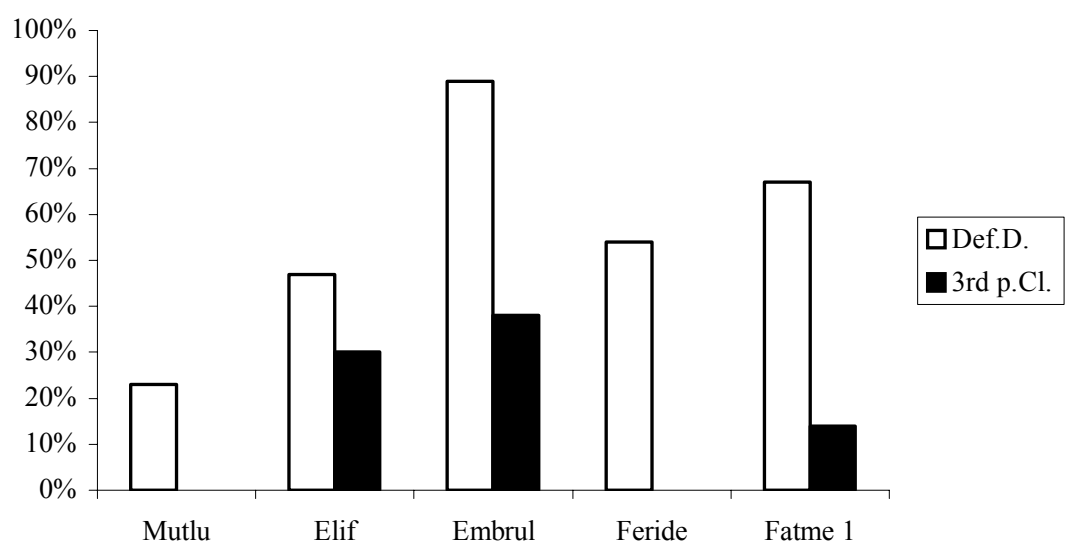

Figure 2.

Comparison between use of definite article and third-person VP-clitic in group 1

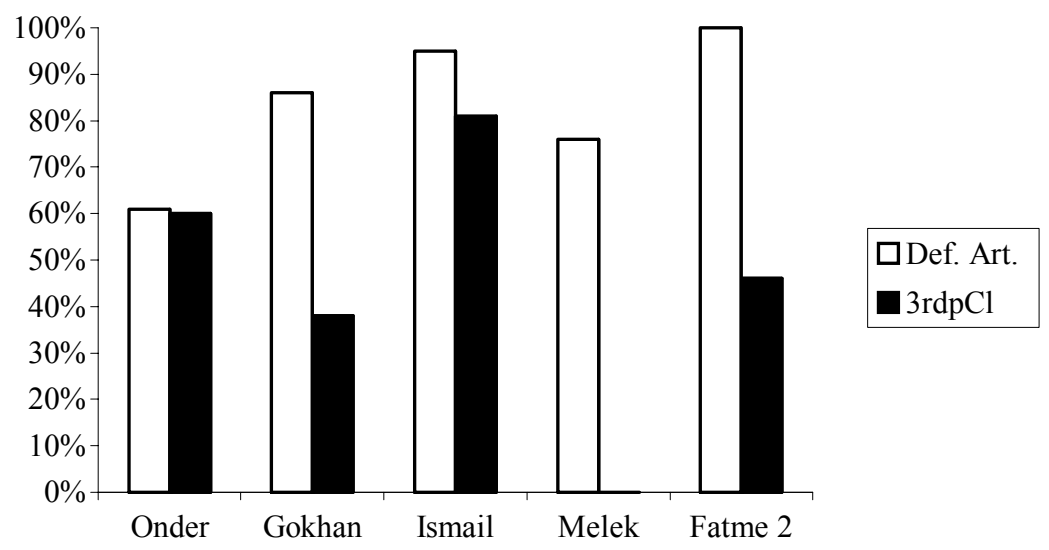

Figure 3.

Comparison between use of definite article and third-person VP-clitic in group 2 
168 Tsimpli and Mastropavlou

Although better performance is found in the use of both elements in Group 2, it is clear that the definite article shows more targetlike use overall than the thirdperson clitic.

The pattern shown in the data in Figures 2 and 3 is quite different from that found in the corresponding adult L2 data. Specifically, in both groups of child learners, use of the definite article is better than use of the clitic, and the differences are significant: Group $1\left(\chi_{(1,242)}^{2}=11.56, \mathrm{p}=.001\right)$ and Group $2\left(\chi^{2}\right.$ $(1,269)=31.36, \mathrm{p}=.000)$. It is crucial, however, to note that if Embrul, who appears to perform differently from the other four children in Group 1, is not included, the use of the definite article by Group 1 is very close to that of the adult L2 learners ( $51 \%$ vs. $49 \%)$.

To summarize the child L2 data, the comparison between the definite and the indefinite article shows better performance on the indefinite in the younger group of learners, similarly with the adults. In the older group of children, however, the definite article appears to be almost targetlike and thus shows no difference from the indefinite article. In terms of the interpretability distinction, supporting evidence is provided by the younger group of learners, who show a pattern similar to the adults. Group 2 has progressed to mastery of the definite article unlike adult performance in this domain.

As far as the comparison between VP- and NP-clitics is concerned, the younger group of child learners, unlike adults, shows no difference between omission rates in the two types of clitics, whereas Group 2 shows uneven development; the possessive clitic is used close to target whereas the accusative clitic lags behind, similarly with adults. Thus, Group 2 is similar to adults with respect to accusative clitics but unlike adults with regard to the definite article. Overall then, the priority of the indefinite over the definite article is confirmed by both child and adult data. Accusative clitics remain a problem for both adults and children. Moreover, the parallelism in the overall problematic use of thirdperson clitics and the definite article is found in the younger group of child L2 learners.

\subsection{SLI Data}

Starting with the comparison between the definite and the indefinite article as in the L2 data, use and omission of articles in obligatory contexts are presented in Table 12 below. 
Feature Interpretability in L2 Acquisition and SLI 169

Table 12. Use and omission of articles in obligatory contexts

\begin{tabular}{lllll}
\hline SUBJECTS & DEFINITES & \multicolumn{3}{l}{ INDEFINITES } \\
\hline GROUP 1 & Use & Omission & Use & Omission \\
\hline C.K.- $4 ; 6$ & $23-28 \%$ & $60-72 \%$ & $21-95 \%$ & $1-5 \%$ \\
S.M. $-4 ; 4$ & $12-43 \%$ & $16-57 \%$ & $38-100 \%$ & $0-0 \%$ \\
L.V. $-4 ; 0$ & $21-62 \%$ & $13-38 \%$ & $29-97 \%$ & $1-3 \%$ \\
TOTAL & $56-39 \%$ & $89-61 \%$ & $88-98 \%$ & $2-2 \%$ \\
\hline GROUP 2 & & & & \\
\hline K.K. $-6 ; 2$ & $165-95 \%$ & $9-5 \%$ & $79-90 \%$ & $8-10 \%$ \\
N.P. $-5 ; 6$ & $51-94 \%$ & $3-6 \%$ & $65-100 \%$ & $0-0 \%$ \\
S.L. $-5 ; 9$ & $56-93 \%$ & $4-7 \%$ & $64-94 \%$ & $4-6 \%$ \\
TOTAL & $272-94 \%$ & $16-6 \%$ & $208-95 \%$ & $12-5 \%$ \\
\hline
\end{tabular}

There is a clear development shown in the SLI data. The younger group shows a high rate of omission in obligatory contexts for the definite article, whereas the older group approaches target use. Within-group comparisons show that the difference in the use of the definite and the indefinite article is significant in the younger group $\left(\chi_{(1,234)}^{2}=81.63, \mathrm{p}=<.000,35.8 \%\right.$ vs. $\left.95.6 \%\right)$, and nonsignificant in Group 2 (93.1\% vs. 95\%). Between-group comparisons show significant differences in the use of the definite article $\left(\chi_{(1,432)}^{2}=166.52, p=<\right.$ $.000,35.8 \%$ vs. $93.1 \%$ ) and no significant differences in the use of the indefinite article $(95.6 \%$ vs. $95 \%)$. Some of the sentences produced by these subjects are provided in (17) through (19).

(17) INT.: Pjos efaje ti miti tu?

Who ate his nose?

L.V: *(i) kukuvaja.

(the-nom) owl

(18) S.M.: edho peni *(to) sfii’.

Here takes (the-acc) hammer

(19) Int.: Ti s'aresi esena?

What do you like?

S.L.: $\quad *($ ta $) \quad$ tuvlakja.

(the-acc) building-blocks

Turning to the SLI children's performance on accusative and possessive clitics, the data are presented in Table 13.Similarly with the development found in the definite article, the third-person accusative clitic also shows a developmental difference in the second group. On the other hand, possessive clitics are used targetlike even in the younger group of SLI children. Between-group comparisons confirm this pattern: the difference in the use of the third-person clitic is significant $\left(\chi_{(1,261)}^{2}=55.29, \mathrm{p}=<.000,51.6 \%\right.$ vs. $\left.91.7 \%\right)$, whereas the difference in the possessive clitic is nonsignificant (97.6\% vs. $99.3 \%)$. Withingroup comparisons show significant differences in the use of VP- and NP-clitics in both groups: Group $1\left(\chi_{(1,219)}^{2}=66.67, \mathrm{p}=.000,51.6 \%\right.$ vs. $97.6 \%$, 
170 Tsimpli and Mastropavlou

respectively), Group $2\left(\chi_{(1,308)}^{2}=9.50, p=.002,91.7 \%\right.$ vs. $99.3 \%$, respectively).

Table 13. Use and omission of third-person accusative vs. possessive clitics ${ }^{16}$

\begin{tabular}{lllll}
\hline SUBJECTS & \multicolumn{2}{l}{$3^{\mathrm{RD}}$ PERSON CLITIC } & \multicolumn{2}{l}{ POSSESSIVE CLITICS } \\
\hline GROUP 1 & Use & Omission & Use & Omission \\
\hline C.K.- $4 ; 6$ & $23-50 \%$ & $23-50 \%$ & $42-95 \%$ & $2-5 \%$ \\
S.M. $-4 ; 4$ & $8-32 \%$ & $17-68 \%$ & $38-100 \%$ & $0-0 \%$ \\
L.V. $-4 ; 0$ & $17-77 \%$ & $5-23 \%$ & $44-98 \%$ & $1-2 \%$ \\
TOTAL & $48-52 \%$ & $45-48 \%$ & $124-98 \%$ & $3-2 \%$ \\
\hline GROUP 2 & & & & \\
\hline K.K. $-6 ; 2$ & $72-92 \%$ & $6-8 \%$ & $65-98 \%$ & $1-2 \%$ \\
N.P. $-5 ; 6$ & $33-85 \%$ & $6-15 \%$ & $34-100 \%$ & $0-0 \%$ \\
S.L. $-5 ; 9$ & $50-96 \%$ & $2-4 \%$ & $40-100 \%$ & $0-0 \%$ \\
TOTAL & $155-92 \%$ & $14-8 \%$ & $139-99 \%$ & $1-1 \%$ \\
\hline
\end{tabular}

Examples of use and omission of genitive and accusative clitics are provided in (20) through (22) below.

\begin{tabular}{|c|c|c|c|c|}
\hline (20) S.L: & $\begin{array}{l}\text { gafi } \\
\text { is-writing }\end{array}$ & ena gama. & & \\
\hline INT.: & $\begin{array}{l}\text { ls-writing } \\
\text { kjedho? } \\
\text { and-here? }\end{array}$ & le letter & & \\
\hline S.L.: & $\begin{array}{l}* \text { (to) klini } \\
\text { (it)-closes } \\
\text { "He closes }\end{array}$ & & & \\
\hline (21)L.V: & $\begin{array}{l}* \text { (to) tipite } \\
\text { It-hit-3s }\end{array}$ & $\begin{array}{l}\text { pano to } \\
\text { on the }\end{array}$ & $\begin{array}{l}\text { kefali } \\
\text { head }\end{array}$ & $\begin{array}{l}\text { tu. } \\
\text { his }\end{array}$ \\
\hline (22) S.M: & $\begin{array}{l}\text { "He hit it or } \\
\text { edho *(tin)- } \\
\text { Here (her) }\end{array}$ & $\begin{array}{l}\text { his head." } \\
\text { pjani. } \\
\text { catches }\end{array}$ & & \\
\hline INT: & $\begin{array}{l}\text { tin-pjani, eh } \\
\text { "He catches }\end{array}$ & $\begin{array}{l}\text { ?, ke ti tin ka } \\
\text { her, eh? An }\end{array}$ & $\begin{array}{l}\text { ii? } \\
\text { what do }\end{array}$ & he do to her?' \\
\hline S.M: & $\begin{array}{l}\text { *(tin)-kani } \\
\text { (her)-does } \\
\text { "he lifts her }\end{array}$ & & & \\
\hline
\end{tabular}

Within-group comparisons show that there is a significant difference in the use of the definite article and the clitic in the younger SLI group $\left(\chi_{(1,237)}^{2}=5.77 \mathrm{p}=\right.$

16 The current analysis includes only third-person clitics as there were no obligatory contexts of first- and second-person accusative clitics the SLI children's speech. As for genitive clitics, the only occurrence of first-person clitics was in the expression 'dhiko mu' (=mine), which was stereotypically used by some SLI children and was therefore excluded from the analysis. No second-person genitive clitics were used. 
Feature Interpretability in L2 Acquisition and SLI 171

$<.016,35.8 \%$ vs. $51.6 \%$ ) whereas the difference is nonsignificant in the older SLI group (93.1\% vs. $91.7 \%$ ). Notice that in the younger group, use of clitics is better than use of the definite article, although in neither case can we speak of above-chance performance. The older SLI group (see Figure 4), on the other hand, shows almost target performance on both elements.

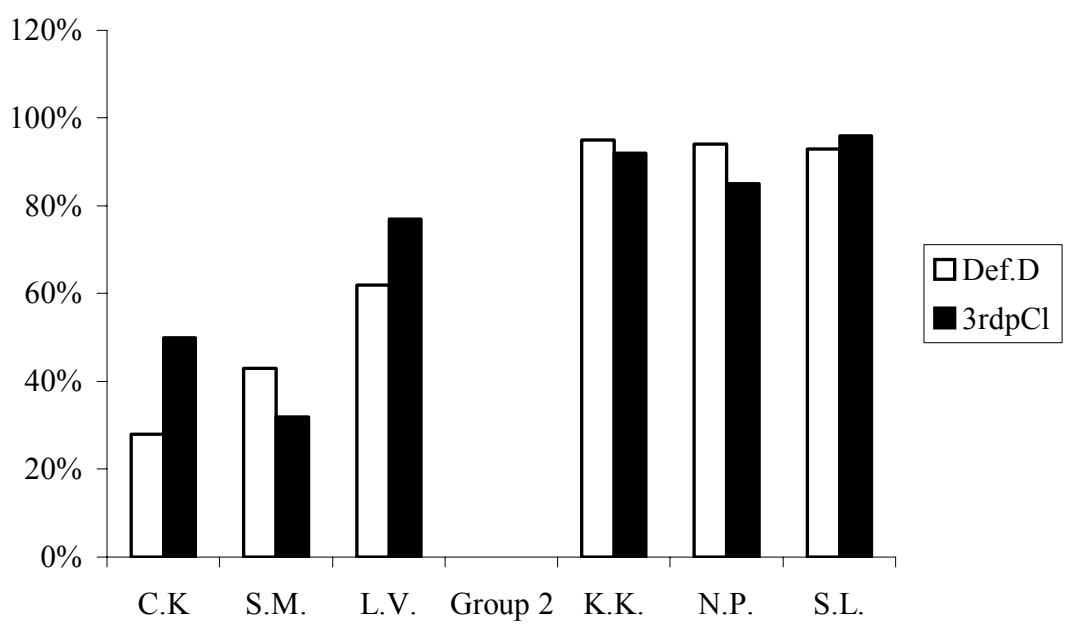

Figure 4. Use of the definite article and third-person accusative clitics

To summarize the results from the SLI data, the indefinite article and the possessive clitics show no problems for either group of children. On the other hand, the definite article and the third-person accusative clitic are problematic for the younger group. The relevant contrast between genitive and accusative clitics on one hand, and definite/indefinite articles on the other, support the predictions based on the interpretability distinction.

\section{DISCUSSION}

\subsection{The Article System}

Concentrating on the similarities found in the performance of child and adult L2 learners as well as SLI children, we observe the following pattern. In the article paradigm, the indefinite contrasts with the definite article: The indefinite is used almost targetlike, whereas the definite article shows a developmental pattern in the SLI children and the child L2 learners. Specifically, the younger group of subjects, in each case, shows optional use of the definite article, whereas the older group appears to have mastered its use in obligatory contexts. Adult L2 


\section{Tsimpli and Mastropavlou}

learners show the discrepancy in the use of the definite and the indefinite article in that the latter is used nativelike, whereas the former is far from targetlike in the data from all the subjects.

In terms of the theoretical predictions made for the definite and the indefinite article, the adult, child L2, and SLI data appear to confirm them, giving rise to the differences summarized above. The fact that, unlike the adult L2 learners, the older group of SLI and child L2 learners have acquired the definite article points to the possibility that the age difference is crucial for acquiring morphosyntactic features that are clusters of uninterpretable featurevalues of case and agreement. However, acquisition is considerably delayed compared to the average L1 learner (Marinis, 2002; Mastropavlou \& Marinis, 2002; Tsimpli, 2005). In the case of SLI children, the delay observed may be the result of a genetically based reduced ability to syntactically analyze the L1 input or the result of a deficit in the syntactic system, which requires considerably more exposure to the input in order to achieve targetlike performance indirectly, that is, via a learning rather than an acquisition process (Curtis, Katz, \& Tallal, 1992; Morehead \& Ingram, 1973; Rice, 2004).

In the case of the older group of child L2 learners, on the other hand, targetlike performance in the Greek article system cannot be viewed from a similar perspective. Notice that, unlike L1 learners, this group of Turkish L2 learners shows the predicted developmental difference between the two articles in that the indefinite is mastered earlier than the definite. Therefore, we cannot conclude that L2 acquisition in these children is similar to L1 acquisition. In addition, mastery of either the definite or the indefinite articles cannot be based on L1 Turkish given that in this language it is possible to use bare nouns with a definite or indefinite interpretation. ${ }^{17} \mathrm{We}$ can then conclude that acquisition of the article system in child L2 grammars can be attained, in contrast with adult L2 grammars, due to differences based on age. Although this is highly speculative, it is possible that the inaccessibility of uninterpretable features in L2 grammars that are beyond the critical period forces the learner to look for interpretable properties of the L2 only. In the case of L2 learners who are still, arguably, within the critical period for language acquisition, uninterpretable features can be analyzed and integrated in the L2 grammar eventually, but not by following the same route taken by L1 learners (see discussion on clitics in the next section).

Overall then, the only advanced group of learners who show optional use of the definite article is the adult L2 learners. On closer examination of their data, however, optionality of the definite article appears to be related to the type of noun phrase used. Specifically, if we distinguish between proper names, demonstrative noun phrases, and possessive noun phrases (most of which include kinship terms), a different pattern of use/omission of the definite article

${ }^{17}$ The specificity marker bir can be considered to function like an indefinite article but only in contexts where the noun has a specific indefinite interpretation (Kornfilt, 1997). In this respect, it grammaticalizes specificity rather than (in)definiteness. 
emerges. The choice of these types of noun phrases is based on a) the fact that kinship terms (with possessive clitics) form a relatively large category of noun phrases used by these L2 learners, b) that proper names and demonstrative noun phrases involve obligatory and expletive use of the definite article, and c) that the demonstrative noun phrases seem to present learners with strong phonological cues of agreement between the demonstrative and the noun, as shown by the examples in (23).
(23)a. afto
to vivlio
this-nom/acc the-nom/acc book-Neuter
"this book"
b. afti $\mathrm{i} / \mathrm{ti}$
this-nom the-nom/the-acc girl-Fem.
"this girl"
c. aftos o / afton ton anthropo
this-nom the-nom / this-acc the-acc man-Masc.
"this man"

It is then possible that although the article is used expletively in the demonstrative noun phrase, it will show a different pattern of omission or use compared to proper names where no such phonological cues are involved or to kinship terms where the use of the definite article inherits referentiality from the interpretation of the head noun. Examples of kinship terms from the L2 data are provided in (24).

$$
\begin{aligned}
& \text { (24)a. *(o) andras mu dhulevi poli.. } \\
& \text { (the-nom) husband-nom my work-3s a lot } \\
& \text { “...my husband works hard..." } \\
& \text { b. ..filane *(ta) pedhia mu ... } \\
& \text { look-after-3p children-acc my } \\
& \text { "They look after my children." }
\end{aligned}
$$

\begin{tabular}{|c|c|c|c|c|c|c|}
\hline & USE & & & OMISSION & & \\
\hline Subject & Possessives & $\begin{array}{l}\text { Proper } \\
\text { names }\end{array}$ & $\begin{array}{l}\text { Dem+ } \\
\text { D }\end{array}$ & Possessives & $\begin{array}{l}\text { Proper } \\
\text { names }\end{array}$ & Dem+D \\
\hline Marika & $29 \%$ & $4 \%$ & $4 \%$ & $33 \%$ & $17 \%$ & 0 \\
\hline Midhia & $17 \%$ & $10 \%$ & 0 & $22 \%$ & $17 \%$ & 0 \\
\hline Afroditi & $40 \%$ & $3 \%$ & $10 \%$ & $41 \%$ & $16 \%$ & 0 \\
\hline Zanna & $22 \%$ & $13 \%$ & $8 \%$ & $9 \%$ & $31 \%$ & 0 \\
\hline Lamara & $38 \%$ & $10 \%$ & $38 \%$ & $28 \%$ & $24 \%$ & $6 \%$ \\
\hline Toma & $40 \%$ & $6 \%$ & $11 \%$ & $33 \%$ & $15 \%$ & 0 \\
\hline
\end{tabular}

In Table 14, the proportion of each of these three categories in the total number of contexts for use and omission of the definite article is provided.

Table 14. Possessives, expletives and Dem $+\mathrm{D}$ contexts in the total number of contexts of 


\section{Tsimpli and Mastropavlou}

In Figure 5, the contrast between use and omission of the definite article in the group results is illustrated.

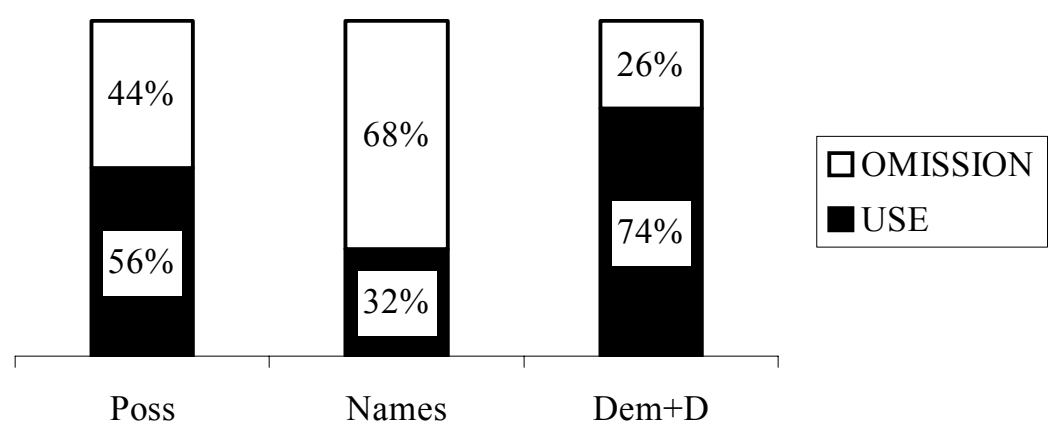

Figure 5: Omission vs. use in possessives, Dem+D and proper names

The difference between each pair is significant: Dem+D/Names $\left(\chi_{(1,135)}^{2}=\right.$ $39.10, \mathrm{p}=.001)$, Dem+D/Poss. $\left(\chi_{(1,256)}^{2}=5.93, \mathrm{p}=.015\right)$, Names/Poss. $\chi_{(1,298)}^{2}$ $=31.12, \mathrm{p}<.001)$. The distinct pattern observed in each category of noun phrases can be analyzed in the following way: In proper names, where the use of the definite article is purely expletive, learners show a strong preference for omission. In the demonstrative contexts, phonological cues lead the learner to apparently targetlike use in the majority of contexts, as a result of a "learned" combination of the demonstrative and the article. Finally, in possessive noun phrases we find real optionality in the use of the article. If we assume that the learners are at the second (and final) stage of (mis)analyzing the features of the Greek definite article, it is possible that they assign to it a specificity value as an interpretable feature. If this is the case, and assuming that possessive noun phrases are [ + specific] due to the kinship term used together with the possessive clitic, they are unambiguous in reference. The adult L2 grammar considers use of the definite article compatible with the interpretation of this type of noun phrase. Notice that the optionality in the use of the article indicates that compatibility in terms of features does not imply obligatory use. A possible explanation is that the interpretable feature of specificity is already marked on the noun+poss. clitic, and thus the article is an additional marker of specificity. On the other hand, since the L2 grammar has not analyzed the article as a D element with case and agreement features exclusively, it fails to assign to it the obligatory status that it has in the target language, that is, as a marker of nominal or nominalized arguments. Finally, if the definite article in the adult L2 grammar is marked for specificity, then its expletive use is not compatible with proper 
Feature Interpretability in L2 Acquisition and SLI 175

names, hence the difference in use/omission found in the above contexts. ${ }^{18}$

\subsection{The Clitic System}

With respect to the clitic system, the evidence from L2 learners (child and adult) and SLI children points to a similar pattern: first-/second-person clitics and possessive clitics are used more accurately than are third-person accusative clitics. This result supports the interpretability distinction according to which third-person clitics were argued to differ from the other members of the clitic paradigm. Concentrating on the differences between groups, note that SLI children show the developmental pattern found in the definite article: The thirdperson clitic is mastered by the older but not the younger group, whereas possessives are unproblematic for both groups of SLI children. Therefore, development in the SLI children shows a correlation in the mastery of thirdperson clitics and the definite article, as predicted by the adopted analysis, which considers the two elements as being similar categorially and in featurespecification.

The correlation in the use of third-person clitics and the definite article is also supported by the younger group of child L2 learners and by adult L2 learners. However, the older group of child L2 learners shows a contrast between the third-person clitic and the definite article. Specifically, although the definite article is acquired, the accusative clitic is not ( $89 \%$ vs. $56 \%)$. Adult L2 learners who, unlike the older group of child L2 learners, fail to show successful performance in the definite article, also show optional use of third-person clitics, similarly with the child L2 data (although children show a higher rate of successful use than adults: $56 \%$ vs. $37 \%$ ). The picture that emerges then is the following: Adult L2 learners perform similarly with the younger group of child L2 learners with respect to both the definite article and the third-person clitic. The older group of child L2 learners, on the other hand, differs from the adults

18 An anonymous reviewer points out that if the definite article is endowed with an interpretable feature, then it should be used equally successfully with the indefinite article. This is a plausible implication; however, in order to test its validity, the investigation should include a semantic/pragmatic search for contexts in the L2 data where the referent is [+specific]. The contexts in Figure 5 include the [+specificity] feature only with respect to the kinship terms, that is, Poss. In these contexts, the definite article is not responsible for marking specificity on its own; it just "agrees" with the specific interpretation derived semantically or, in any case, compositionally at the DP level. Thus, although we agree with the reviewer that the L2 grammar should show almost targetlike use of the definite article, similarly with the indefinite, the analysis should take into account all [+specific] DPs used by the speaker, in which specificity is not expressed lexically or compositionally (as in the case of kinship possessive structures). It is this set of DPs that constitutes the total number of obligatory contexts for use of the L2 definite article, endowed with an interpretable feature. Thus, the distribution of the contexts presented in Figure 5 does not provide counterevidence to the proposed analysis of the definite article in advanced L2 Greek. 
176 Tsimpli and Mastropavlou

with regard to the definite article but not the clitic. The question that arises is what is the cause of the dissociation between the two elements found in the older group of children? In particular, if, as argued in the previous section, child L2 acquisition allows for access to uninterpretable features and the data from the definite article are compatible with this suggestion, what prevents children from acquiring target use of the third-person clitic?

Given that Slavic languages and Turkish allow for object drop in contexts where the null object has specific reference, L1 transfer of object drop to Greek L2 is a very strong possibility. Notice, however, that neither of the L1s has clitic pronouns of the Greek type. Therefore, for L1 transfer to take place, misanalysis of Greek clitics as weak pronouns (of the L1 type) is required. In this case, there are two alternatives:

1. L1 interference at the syntax/pragmatics level. According to this option, null objects with specific reference are transferred from L1 (weak pronouns) to L2 clitics. This is syntactically possible due to the misanalysis of the L2 clitics as weak pronouns, and interpretatively possible due to the [+specific] feature of the null object. However, if this type of interference was appropriate to account for object omission, then (a) we shouldn't find a correlation in the development of third-person clitic and the definite article as we do in the adult L2 learners and the younger group of children, because the categorial and feature-based identity between the two elements would not be available; (b) child L2 learners who have acquired the definite article should also use clitics more than they do, because they have acquired the $\mathrm{D}$ category with its appropriate featurespecification; thus, child L2 learners should have reached a stage where the Greek clitic should not be misanalyzed; and (c) there should be parallel object drop of first-/second- and third-person clitics, given that all of the corresponding weak pronouns in $\mathrm{L} 1$ can be dropped.

2. L1 interference of lexical case. Clitics are obligatory in Greek because they are D elements which host Case. Argument licensing (and identification) is therefore associated with the D element (clitic) responsible for identifying the object in terms of its formal phi-features and case (Roussou \& Tsimpli, in press). Similar formal properties are associated with the definite article. Overall then, the D category (clitics or DPs) licenses arguments in Greek. On the other hand, in Russian and Turkish, Case is a feature associated with nouns (lexical category). In this respect, Russian has been argued to have lexical rather than structural case, whereas arguments are not DPs but rather KPs or NPs (Kowaluk, 2001). It is this parametric property associated with lexical as opposed to structural case, that is not reset in the L2 learners of this study. Accordingly, identification and licensing of null objects is not an instance of clitic-drop in the Greek L2 of these learners but an L1 option of null pro-N elements (see Kowaluk, 2001, for an analysis of Polish object drop along these lines). The possibility of transferring this empty category is thus associated with the misanalysis of Case as lexical rather than structural. This misananalysis is 
closely related to the lack of a targetlike D system, which primarily spells out case features in Greek.

The question is, of course, how does the Greek definite article carry case when used by these L2 learners, if case is lexical in these learners' Greek? Note that whether or not a D category is grammaticalized in a particular language does not correlate with morphological case in the language. Thus, both Greek and Russian show a case paradigm. Moreover, in both languages, case appears on every element in the nominal domain, for example, (D) -QuantifierAdjective-Noun. It is, nevertheless, assumed that Case is uniquely specified on one of these elements ( $\mathrm{D}$ or $\mathrm{N}$ ) and the remaining items agree with the head $\mathrm{N}$ or $\mathrm{D}$, inside the nominal domain. Thus, the $\mathrm{L} 2$ learners transfer Case on $\mathrm{N}$ from their L1 to Greek L2 even in contexts where a definite article is also used: The definite article agrees in case with the noun used.

If this analysis of null objects in Greek L2 is correct, it follows that child L2 learners who seem to have acquired the definite article do not represent it in the target way as yet. In other words, if they have not as yet analyzed L2 clitics as D elements and Case as structural, high performance on the definite article does not map onto the target representation.

\section{CONCLUSIONS}

The theory advocated in this chapter is based on the interpretability distinction between elements of the article and the pronominal paradigm in Greek. It is argued that within the domain of clitics, third-person accusative clitics are clusters of uninterpretable features only, whereas first-/second-person accusative clitics and possessive clitics include the interpretable [person] feature, which renders them referential. In addition, the definite article is similar to the thirdperson clitic in categorial, case, and agreement features, with no inherent specification for definiteness. The indefinite, on the other hand, is marked as [definite], and as such it should pattern with first-/second-person accusative and possessive clitics, which also bear interpretable features intrinsically.

The data come from sufficiently different populations of learners: child and adult L2 learners and SLI children. However, the learnability theory presented suggests that all groups should show evidence for differential performance in interpretable versus uninterpretable features on the grounds that the latter are difficult to access in any developmental process other than normal L1 development. The underlying reasons for inaccessibility of uninterpretable features are associated with critical period constraints or genetically based deficiencies in the analysis of the input.

Although all groups show the predicted differences in their performance on clitics and articles, there are differences between them. Older SLI children perform targetlike on third-person clitics and the definite article, showing that prolonged exposure to the input can lead to successful production in natural 


\section{Tsimpli and Mastropavlou}

contexts. The older group of child L2 learners is successful in the definite article but not the third-person clitic. This discrepancy has been argued to stem from the transfer of pro-N drop given the representation of case as lexical rather than structural. Thus, object drop in these children is not clitic-drop but a transferred L1 property. It should be noted, however, that child L2 learners are predicted to perform, eventually, nativelike on clitics too. This prediction is based on the suggestion that the definite article has been acquired, and therefore uninterpretable features are accessible to the L2 grammar. ${ }^{19}$ Finally, adult L2 learners have been argued to show persistent problems with both the clitic and the definite article. Clitic omission in their data receives a similar analysis to the child L2 data: Greek clitics are not analyzed as D elements but as weak pronouns of the L1 type instead. If case features are not licensing features for argumenthood in the L1, then pronouns can be dropped in both L1 and L2. The fact that adult L2 learners show poor performance in the use of the definite article compared to child L2 learners is argued to stem from the inaccessibility of uninterpretable features. This leads them to misanalyze the Greek definite article as an element bearing a specificity feature in order to partly regulate its distribution. It is argued that this process is the second stage of misanalysis in adult L2 acquisition which attempts to remedy unconstrained optionality in UGconstrained grammars.

\section{ACKNOWLEDGMENTS}

Earlier versions of this chapter have been presented at GASLA, Ottawa, UCL, and Cambridge. We are grateful to the audiences there. We also thank Eleni Agathopoulou, Maria Dimitrakopoulou, Anna Roussou, and Neil Smith for discussions on various issues addressed in the chapter. All errors remain, of course, our responsibility.

\section{REFERENCES}

Agouraki, G. (1993). Spec-head licensing: The scope of the theory. Unpublished doctoral thesis, University of London.

Alexiadou, A., \& Anagnostopoulou, E. (1998). Parametrizing Agr: Word order, verbmovement and EPP-checking. Natural Language and Linguistic Theory, 16(3), 491539 .

Alexiadou, A., \& Anagnostopoulou, E. (2001). The subject in situ generalisation, and the role of Case in driving computations. Linguistic Inquiry, 32, 193-231.

Bibis, N., \& Roberge, Y. (2004). Marginal clitics. Lingua, 114, 1015-1034.

${ }^{19}$ On this prediction, child L2 learners of Greek with L1s that have an article system but no clitics (e.g., English learners of Greek) are expected to acquire the Greek article and the Greek clitic in parallel. 
Birdsong, D. (1992). Ultimate attainment in second language acquisition. Language, 68, $706-755$.

Bishop, D., \& Adams, C. (1990). A prospective study of the relationship between specific language impairment, phonological disorders and reading retardation. Journal of Child Psychology and Psychiatry, 31, 1027-1050.

Bloom, L., \& Lahey, M. (1978). Language development and language disorders. New York: Wiley.

Bottari, P., Chilosi, M., \& Pfanner, L. (1998). The determiner system in a group of Italian children with SLI. Language Acquisition, 7, 285-315.

Bottari, P., Cipriani, P., Chilosi, A. M., \& Pfanner, L. (2001). The Italian determiner system in normal acquisition, specific language impairment, and childhood aphasia. Brain and Language, 77(3), pp.283-293.

Cardinaletti, A., \& Starke, M. (1999). The typology of structural deficiency: A case study of the three classes of pronouns. In H. van Riemdijk (Ed.), Clitics in the languages of Europe (pp. 273-290). Berlin: Mouton de Gruyter.

Chomsky, N. (1995). The minimalist program. Cambridge, MA: MIT Press.

Chomsky, N. (2001). Beyond the explanatory adequacy. MIT Working Papers in Linguistics, 20.

Clahsen, H., (1989). The grammatical characterization of developmental dysphasia. Linguistics, 27, 897-920.

Clahsen, H. (1991). Child language and developmental dysphasia: Linguistic studies in the acquisition of German. Amsterdam: John Benjamins.

Clahsen, H., Bartke, S., \& Gollner, S. (1997). Formal features in impaired grammars: A comparison of English and German SLI children. Essex Research Reports in Linguistics, 14, 42-75.

Coppieters, R. (1987). Competence differences between native and near-native speakers. Language, 63, 544-573.

Curtis, A., Katz, S. W., \& Tallal, P. (1992). Delay vs. deviance in the language acquisition of language impaired children. Journal of Speech and Hearing Research, $35,373-383$.

Eubank, L. (1994). Optionality and the initial state in L2 development. In T. Hoekstra \& B. Schwartz (Eds.), Language acquisition studies in generative grammar (pp.183208). Amsterdam: John Benjamins.

Fodor, J. D., \& Inoue, A. (2000). Syntactic features in reanalysis: Positive and negative symptoms. Journal of Psycholinguistic Research, 29, 25-36.

Franks, S. \& T. H. King (2000). A Handbook of Slavic Clitics. New York, NY: Oxford University Press.

Genesee, F., Paradis, J., \& Crago, M. (2004). Dual language development and disorders: $A$ handbook on bilingualism and second language learning. Baltimore: Brookes.

Giannakidou, A., \& Stavrou, M. (1999). Nominalization and ellipsis in the Greek DP. The Linguistic Review, 16, 295-331.

Giusti, G. (1997). The categorial status of determiners. In L. Haegeman (Ed.), The new comparative syntax (pp. 95-123). London: Longman.

Goad, H. (1998). Plurals in SLI: Prosodic deficit or morphological deficit? Language Acquisition, 7(2-4), 247-284.

Gopnik, M. (1990). Feature-blind grammar and dysphasia. Nature, 344, 715.

Gopnik, M., \& Crago, M. B. (1991). Familial aggregation of a developmental language disorder. Cognition, 39, 1-50. 
180 Tsimpli and Mastropavlou

Halpern, A. \& J. M. Fontana (1994). "X $\mathrm{X}^{0}$ Clitics and Xmax Clitics". Proceedings of the West Coast Conference on Formal Linguistics (WCCFL XII). Stanford, CA: CSLI Publications.

Hawkins, R. (2001). Second language syntax: A generative introduction. Malden, MA: Blackwell.

Hawkins, R., \& Chan, C. (1997). The partial availability of UG in second language acquisition: the "failed functional features hypothesis". Second Language Research, 13(3), pp.187-226.

Haznedar, B., \& Schwartz, B. D. (1997). Are there optional infinitives in child L2 acquisition? In E. Hughes, M. Hughes, \& A. Greenhill (Eds.), Proceedings of the 21st Annual Boston University Conference on Language Development (Vol. 1), pp.257-268). Somerville, MA: Cascadilla Press.

Jakubowicz, C., \& Nash, L. (2001). Functional categories and syntactic operations in (ab)normal language acquisition. Brain and Language, 77, 321-339.

Jakubowicz, C., Nash, L., Rigaut, C., \& Gérard, C. L., (1998). Determiners and clitic pronouns in French-speaking children with SLI. Language Acquisition, 7(2-4), 113160.

Johnson, J. S., \& Newport, E. L. (1989). Critical period effects in second language learning: The influence of maturational state on the acquisition of English as a second language. Cognitive Psychology, 21, 60-99.

Johnson, J., \& Newport, E.L. (1991). Critical period effects on universal properties of language: The status of subjacency in the acquisition of a second language. Cognition 39, 215-258.

Karanasios, Y. (1992). Syntaxe comparée du groupe nominal en grec moderne et dans d'autres langues. Unpublished doctoral dissertation. Université Paris VIIIVincennes.

Kayne, R. (1989). Facets of Romance past participle agreement. In P. Benincà (Ed.), Dialect variation and the theory of grammar (pp.85-103). Dordrecht, Netherlands: Foris.

Kayne, R. (1991). Romance clitics, verb movement, and PRO. Linguistic Inquiry, 22, 647-686.

Kiss, È. K. (1998). Identificational focus versus information focus. Language, 74, 245273.

Kornfilt, J. (1997). Turkish grammar. London: Routledge.

Kowaluk, A. (2001). The acquisition of pronouns and determiners in English L2. Unpublished doctoral dissertation, University of Cambridge, UK.

Lakshmanan, U. (1994). [Review of J. Meisel (Ed.), The acquisition of verb placement. Kluwer Academic Publishers, 1992]. Studies in Second Language Acquisition, 16(3), 357-358.

Lardiere, D. (2000). Mapping features to form in second language acquisition. In J. Archibald (Ed.), Second language acquisition and linguistic theory (pp. 102-129). Oxford, UK: Blackwell.

Leonard, L., Bortolini, U., Caselli, C., McGregor, K., \& Sabbadini, E. (1992). Morphological deficits in children with specific language impairment: The status of features in the underlying grammar. Language Acquisition, 2, 151-179.

Levy, Y., \& Schaeffer, J.C. (2003). Language competence across populations. Mahwah, NJ: Lawrence Erlbaum Associates. 
Feature Interpretability in L2 Acquisition and SLI 181

Manzini, M. R., \& Savoia, L. M. (1998). Clitics and auxiliary choice in Italian dialects: Their relevance for the person ergativity split. Recherches linguistiques à Vincennes, 27, 115-138.

Manzini, M. R., \& Savoia, L. M. (2002). Parameters of subject inflection in Italian dialects. In P. Svenonius (Ed.), Subjects, expletives, and the EPP (pp. 157-200). Oxford, UK: Oxford University Press.

Marinis, T., \& Panagiotidis, P. (in press). Determiner spreading as referential predication. Journal of Linguistics.

Marinis, T. (2002). Minimal inquiries and the acquisition of the definite article in modern Greek. In Proceedings of the 34th Colloquium of Linguistics (pp.73-82). Germersheim, Germany: Peter Lang.

Mastropavlou, M. (2003). Simfonia ke ghenos sto logho dhio pedjon me idhiki glossiki djatarakhi [Agreement and gender in the speech of two children with specific language impairment]. Oral presentation in the Second Postgraduate Students' Workshop, Department of Philology, Faculty of Linguistics, University of Athens.

Mastropavlou, M., \& Marinis, T. (2002, June). Definite articles and case marking in the speech of Greek normally developing children and children with SLI. Poster session presented at the EuroConference on the Syntax of Normal and Impaired Language, Corinth, Greece.

Mavridou, V. (2003). Second language acquisition of Greek: evidence from child speakers of Turkish. Unpublished master's thesis, Aristotle University of Thessaloniki, Greece.

McShane, M. (2002). Unexpressed objects in Russian. Journal of Slavic Linguistics, 10, 291-328.

Morehead, D., \& Ingram, D. (1973). The development of base syntax in normal and linguistically deviant children. Journal of Speech and Hearing Research, 16, 330353.

Nash, L., \& Rouveret, A. (2002). Cliticization as unselective attract. Catalan Journal of Linguistics, 1, 157-199.

Panagiotidis, P. (2002). Pronouns, clitics and empty nouns. Amsterdam: John Benjamins.

Paradis, M., \& Gopnik, M. (1994). Compensatory strategies in familial language impairment. McGill Working Papers in Linguistics, 10(1-2), 142-149.

Paradis, M., \& Gopnik, M. (1997). Compensatory strategies in genetic dysphasia: Declarative memory. Journal of Neurolinguistics, 10, 173-185.

Parodi, T., \& Tsimpli, I. (2005). Real and apparent optionality in L2 grammars. Second Language Research, 21(3), 250-85.

Platzack, Ch. (1999). The Subject of Icelandic Psych-Verbs: a Minimalist Account. Working Papers in Scandinavian Syntax, 64, 103-115.

Prévost, P., \& White, L. (2000). Missing surface inflection or impairment in second language acquisition? Evidence from tense and agreement. Second Language Research, 16(2), 103133.

Rice, M. (2004). Growth models of developmental language disorders. In M. L. Rice \& S. F. Waren (Eds.), Developmental language disorders: From phenotypes to etiologies (pp. 207-240). Mahwah, NJ: Lawrence Erlbaum Associates.

Rice, M., \& Wexler, K. (1996). A phenotype of specific language impairment: Extended optional infinitives. In M. L. Rice (Ed.), Toward a genetics of language (pp.215238). Mahwah, NJ: Erlbaum. 
182 Tsimpli and Mastropavlou

Rice, M., Wexler, K., \& Cleave, P. (1995). Specific language impairment as a period of extended optional infinitives. Journal of Speech and Hearing Research, 38, 850 863.

Rizzi, L. (1982). Issues in Italian syntax. Dordrecht, Netherlands: Foris.

Roussou, A., \& Tsimpli, I. M. (in press). On (Greek) VSO again! Journal of Linguistics.

Schwartz, B. D. (2002). Child L2 acquisition: Paving the way. BUCLD Proceedings, 1, $26-50$.

Schwartz, B. D., \& Sprouse, R. A. (1996). L2 cognitive states and the "full transfer/full access" model. Second Language Research, 12(1), 40-72.

Smith, N. V., \& Tsimpli, I. M. (1995). The mind of a savant: Language learning and modularity. Oxford, UK: Blackwell.

Sorace, A. (1999). Initial states, end states and residual optionality in L2 acquisition. In A. Greenhill, H. Littlefield, \& C. Tano (Eds.), Proceedings of the $24^{\text {th }}$ Annual BUCCLD (pp.666 - 674). Somerville, MA: Cascadilla Press.

Sorace, A. (2000). Gradients in auxiliary selection with intransitive verbs. Language, 76, $859-890$

Sperber, D., \& Wilson, D. (1995). Relevance: Communication and cognition. Oxford, UK: Blackwell.

Sportiche, D. (1996). Clitic constructions. In J. Rooryck \& L. Zaring (Eds.), Phrase structure and the lexicon (pp.213-276). Dordrecht, Netherlands: Kluwer.

Sportiche, D. (1999). Subject clitics in French and Romance complex inversion and clitic doubling. In K. Johnson \& I. Roberts (Eds.), Beyond principles and parameters. Essays in memory of Osvaldo Jaeggli (pp.189-221). Dordrecht, Netherlands: Kluwer.

Stavrakaki, S. (2000). Specific language impairment in Greek: Aspects of syntactic production and comprehension. Unpublished doctoral dissertation. Aristotle University of Thessaloniki, Greece.

Stavrou, M. (1996). Adjectives in Modern Greek: An instance of predication or an old issue revisited. Journal of Linguistics, 32, 79-112.

Tsimpli, I. M. (1997). Resumptive features and minimalism: Evidence from second language acquisition. Proceedings of the 21st Annual Boston University Conference on Language Development, 21, 639-655.

Tsimpli, I. M. (2001). LF-interpretability and language development: A study of verbal and nominal features in Greek normally developing and SLI children. Brain and Language, 77, 432-448.

Tsimpli, I. M. (2003). Interrogatives in the Greek/English interlanguage: A minimalist account. In E. Mela-Athanasopoulou (Ed.), Selected papers on theoretical and applied linguistics (pp.214-225). Thessaloniki, Greece: Dept. of Theoretical \& Applied Linguistics, School of English, Aristotle University.

Tsimpli, I. M. (2004). Interprétabilité de traits et acquisition des langues maternelle et seconde: clitiques et determinants en Grec. Acquisition et Interaction en Langue Étrangère, 20, 87-128.

Tsimpli, I. M. (2005). Peripheral positions in early Greek. In M. Stavrou \& A. Terzi (Eds.), Advances in Greek generative syntax: In honor of Dimitra Theophanopoulou-Kontou (pp. 179-216). Amsterdam: John Benjamins.

Tsimpli, I. M., Sorace, A., Heycock, C., \& Filiaci, F. (2004). First language attrition and syntactic subjects: A study of Greek and Italian near-native speakers of English. International Journal of Bilingualism, 8, 257-277. 
Feature Interpretability in L2 Acquisition and SLI 183

Tsimpli, I. M., \& Stavrakaki, S. (1999). The effects of a morphosyntactic deficit in the determiner system: The case of a Greek SLI child. Lingua, 108, 31-85.

Vainikka, A., \& Young-Scholten, M. (1996). Gradual development of L2 phrase structure. Second Language Research, 12(1), 7-39.

van der Lely, H. K. J. (1994). Canonical linking rules: Forward vs. reverse linking in normally developing and specifically impaired children. Cognition, 51, 29-72.

van der Lely, H. K. J. (1996). Specifically language impaired and normally developing children: Verbal passive vs. adjectival passive sentence interpretation. Lingua, 98, 243-272.

van der Lely, H. K. J. (2003). Do heterogeneous SLI deficits need heterogeneous theories? SLI subgroups, G-SLI and the RDDR hypothesis. In Y. Levy \& J. Schaeffer (Eds.), Towards a definition of specific language impairment (pp.109134). Mahwah, NJ: Lawrence Erlbaum Associates.

White, L. (1989). Universal grammar and second language acquisition. Amsterdam: John Benjamins.

White, L. (2003). Second language acquisition and Universal Grammar. Cambridge, UK: Cambridge University Press.

White, L., \& Genesee, F. (1996). How native is near-native? The issue of ultimate attainment in adult second language acquisition. Second Language Research, 12, $233-265$.

Zagona, K. (2002). The syntax of Spanish. Cambridge, UK: Cambridge University Press. Zlatić, L. (1998). Slavic noun phrases are NPs not DPs. Proceedings of the Workshop on Comparative Slavic Morphosyntax. Bloomington, Indiana. 